Provided for non-commercial research and education use. Not for reproduction, distribution or commercial use.

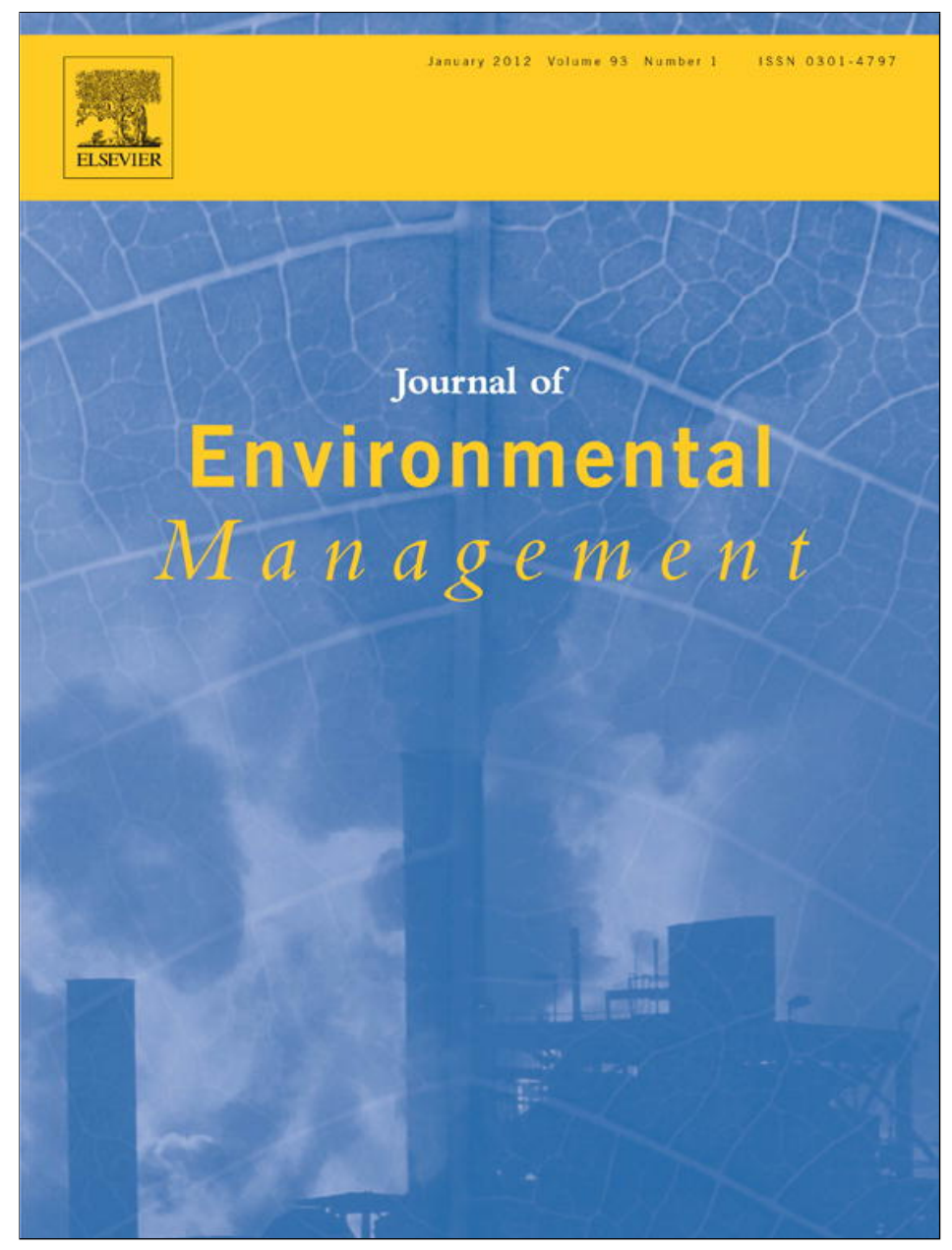

(This is a sample cover image for this issue. The actual cover is not yet available at this time.)

This article appeared in a journal published by Elsevier. The attached copy is furnished to the author for internal non-commercial research and education use, including for instruction at the authors institution and sharing with colleagues.

Other uses, including reproduction and distribution, or selling or licensing copies, or posting to personal, institutional or third party websites are prohibited.

In most cases authors are permitted to post their version of the article (e.g. in Word or Tex form) to their personal website or institutional repository. Authors requiring further information regarding Elsevier's archiving and manuscript policies are encouraged to visit:

http://www.elsevier.com/copyright 


\title{
A new spatial multi-criteria decision support tool for site selection for implementation of managed aquifer recharge
}

\author{
M. Azizur Rahman ${ }^{\mathrm{a}, *}$, Bernd Rusteberg ${ }^{\mathrm{a}}$, R.C. Gogu ${ }^{\text {b,d }}$, J.P. Lobo Ferreira ${ }^{\mathrm{c}}$, Martin Sauter ${ }^{\mathrm{a}}$ \\ ${ }^{a}$ Geoscience Center, Georg-August University of Göttingen, Goldschmidtstr. 3, D-37077 Göttingen, Germany \\ ${ }^{\mathrm{b}}$ Technical University of Civil Engineering, B-dul Lacul Tei, Nr.124, Sector 2, RO- 020296 Bucharest, Romania \\ ${ }^{\mathrm{c}}$ National Laboratory for Civil Engineering (LNEC), AV DO BRASIL 101, 1700-066 Lisbon, Portugal \\ ${ }^{\mathrm{d}}$ Research Institute for Artificial Intelligence, Romanian Academy, Calea 13 Septembrie, 13, RO-050711, Bucharest, Romania
}

\section{A R T I C L E I N F O}

\section{Article history:}

Received 26 October 2010

Received in revised form

14 October 2011

Accepted 5 January 2012

Available online $\mathrm{xxx}$

Keywords:

Artificial recharge

Site selection

Spatial multicriteria analysis

Decision support

Querença-Silves aquifer

\begin{abstract}
A B S T R A C T
This study reports the development of a new spatial multi-criteria decision analysis (SMCDA) software tool for selecting suitable sites for Managed Aquifer Recharge (MAR) systems. The new SMCDA software tool functions based on the combination of existing multi-criteria evaluation methods with modern decision analysis techniques. More specifically, non-compensatory screening, criteria standardization and weighting, and Analytical Hierarchy Process (AHP) have been combined with Weighted Linear Combination (WLC) and Ordered Weighted Averaging (OWA). This SMCDA tool may be implemented with a wide range of decision maker's preferences. The tool's user-friendly interface helps guide the decision maker through the sequential steps for site selection, those steps namely being constraint mapping, criteria hierarchy, criteria standardization and weighting, and criteria overlay. The tool offers some predetermined default criteria and standard methods to increase the trade-off between ease-ofuse and efficiency. Integrated into ArcGIS, the tool has the advantage of using GIS tools for spatial analysis, and herein data may be processed and displayed. The tool is non-site specific, adaptive, and comprehensive, and may be applied to any type of site-selection problem. For demonstrating the robustness of the new tool, a case study was planned and executed at Algarve Region, Portugal. The efficiency of the SMCDA tool in the decision making process for selecting suitable sites for MAR was also demonstrated. Specific aspects of the tool such as built-in default criteria, explicit decision steps, and flexibility in choosing different options were key features, which benefited the study. The new SMCDA tool can be augmented by groundwater flow and transport modeling so as to achieve a more comprehensive approach to the selection process for the best locations of the MAR infiltration basins, as well as the locations of recovery wells and areas of groundwater protection. The new spatial multicriteria analysis tool has already been implemented within the GIS based Gabardine decision support system as an innovative MAR planning tool.
\end{abstract}

๑) 2012 Elsevier Ltd. All rights reserved.

\section{Introduction}

In the field of Water Resources Planning and Management, managed aquifer recharge (MAR) is becoming an important solution for mitigating water scarcity related problems in arid and semi-arid areas. MAR has been practiced throughout the world for the recovery of groundwater levels, improvement of

\footnotetext{
* Corresponding author. Tel.: +49 551 399397; fax: +49 551399379.

E-mail addresses: mohammad-azizur.rahman@geo.uni-goettingen.de (M.A. Rahman), bernd.rusteberg@geo.uni-goettingen.de (B. Rusteberg), radu.gogu@ utcb.ro (R.C. Gogu), Iferreira@Inec.pt (J.P. Lobo Ferreira), msauter1@gwdg.de (M. Sauter).
}

groundwater quality, storage of surface water in the sub-surface, and as a barrier to salinity intrusion. Depending on the water source, water quality, geology, surface conditions, soils, and hydrogeology, a variety of methods have been developed to recharge groundwater (Bouwer, 2002). The spreading basin technique (infiltration) is widely practiced and is useful in areas with high land availability, highly permeable soil, and where the hydrogeology allows for infiltration to an unconfined aquifer (Ghayoumian et al., 2005). Other MAR techniques employing injection wells require less area but a better quality of source water due to the fact that the water is directly injected into the aquifer without taking advantage of natural attenuation processes within the vadose zone. The interdependency of the water quality, 
MAR location, and technology makes project planning multifaceted and complex.

Many factors need to be considered during the site selection process for MAR projects. Complex regional characteristics, heterogeneities in surface and/or subsurface characteristics, and variable groundwater qualities make site selection for MAR difficult (Anbazhagan et al., 2005). Apart from these hydrogeological considerations, other factors such as political and social factors are important in the decision-making process. National and international water policies, natural conservation regulations, environmental impact assessments, and socio-economic considerations make the site selection procedure complex. Complexity increases when MAR project managers are from different disciplinary backgrounds; this may often lead to disagreements concerning which criteria to give more weight in the decision-making process. These conflicts always need to be dealt before the MAR project is implemented. GIS and the traditional Decision Support Systems (DSS) alone do not effectively facilitate the implementation of MAR project parameters, which are equally based on complex decision criteria and spatial information (Jun, 2000). GIS based analysis methods are poor in dealing with uncertainty, risks, and potential conflicts; therefore, there is a large possibility of losing important information, which in turn may lead to a poor decision (Bailey et al., 2003). Multi-Criteria Decision Analysis (MCDA) integrated into GIS (SMCDA) provide adequate solution procedures to this problem because the analysis of potential MAR projects may be done more comprehensively and at a lower cost. Variable project sites, risks, MAR techniques, policies, and limits in geological as well as social, environmental, and political realms can easily be considered by the Spatial Multi-Criteria Decision Analysis (SMCDA) approach (Calijuri et al., 2004).

MCDA is helpful in identifying priorities for a given MAR project (Gomes and Lins, 2002). The integration of MCDA techniques with GIS has considerably advanced the traditional map overlay approaches for site suitability analysis (e.g. Malczewski, 1996; Eastman, 1997). MCDA procedures utilize geographical data, consider the user's preferences, manipulate data, and set preferences according to specified decision rules (Malczewski, 2004). The advantage of integrating GIS with MCDA has been elaborated by many authors (e.g. Malczewski, 1996; Jun, 2000; Gomes and Lins, 2002; Sharifi and Retsios, 2004). According to Malczewski (2004), the two critical considerations for SMCDA are: (i) the GIS capabilities of data acquisition, storage, retrieval, manipulation, and analysis; and (ii) the MCDA capabilities for combining the geographical data and the manager's preference into unidimensional values of alternative decisions. A number of methodologies have already been developed for SMCDA in different fields of science and engineering to select the best alternatives from a set of competing options (e.g. Sharifi et al., 2006; Zucca et al., 2007).

The overlay MCDA plays an important role in many GIS applications. Boolean logic and Weighted Linear Combination (WLC) are the most popular decision rules in GIS (e.g. Eastman, 1997; Malczewski and Rinner, 2005) and both can be generalized within the scope of Ordered Weighted Averaging (OWA) (e.g. Malczewski and Rinner, 2005; Malczewski, 2006). In OWA, a number of decision strategy maps can be generated by changing the ordered weights. Several OWA applications have been implemented already (e.g. Rinner and Malczewski, 2002; Calijuri et al., 2004; Malczewski et al., 2003; Malczewski, 2006). The Analytical Hierarchy Process (AHP), proposed by Saaty (1980), is another wellknown procedure. This procedure is important for spatial decision problems with a large number of criteria (Eastman et al., 1993). AHP can be used to combine the priorities for all levels of a "criteria tree," including the level representing criteria. In this case, a relatively small number of criteria can be evaluated (Jankowski and
Richard, 1994; Boroushaki and Malczewski, 2008). The combination of AHP with WLC and/or OWA can provide a more effective and robust MCDA tool for spatial decision problems. Boroushaki and Malczewski (2008) implemented AHP-OWA operators using fuzzy linguistic quantifiers in the GIS environment, which has been proven to be effective.

An intensive review of the respective literature has indicated that the modern and updated analysis techniques as GIS and MCDA have not been well investigated and compiled in the field of MAR site selection (see the following section for details). In this respect, a structured, non-site specific and flexible decision analysis tool has been developed. In this study, a methodology has been settled up to support the identification of suitable sites by combining modern spatial multi-criteria analysis techniques with decision analysis methods. As consequence, a new tool has been developed to offer the following:

- A comprehensive framework consisting of AHP, WLC, and OWA analysis techniques for spatial multi criteria analysis for MAR site selection.

- A wide range of flexibility and preferences for criteria selection, standardization, and weighting.

- An interactive user interface, which offers the standard techniques and leads the user systematically to complete the site selection process.

This paper includes a review on MAR site selection techniques and may be read at any time as needed for reference purposes (section 2). Section 3 is a description of SMCDA for site suitability analysis and also information on how AHP, suitability mapping, and weighting are involved in the analysis. A brief description on possible sensitivity analysis is done the presentation of a GIS Based Site Suitability Analysis Tool in Section 4. This section together with Section 3 provides distinctive information to MAR site selection. The two sections together are considered to embody the core objective of this paper, which is to explain the development and functionality of a new SMCDA tool for MAR site selection. Section 5 presents the concepts described in Sections 3 and 4 as applied in the field. The case study presented in Section 5 refers to a MAR site selection. It has been developed on the Querenca-Silves aquifer system in Portugal. Section 6 provides a summary of conclusions and recommendations in the scope of future applications and further developments.

\section{The state-of-the-art: MAR site selection techniques}

Only very few studies exist which focus on site selection procedures for Managed Aquifer Recharge (MAR). Respectively, the following three sections differentiate data types (section 2.1), present data processing via GIS (section 2.2), and give reference to the steps involved in site suitability analysis methods (section 2.3) for example, screening of sites, criteria hierarchy and standardization, criteria weighting, overlay, and sensitivity analysis. The three parts of this chapter are intended to serve as a reference for the basic methods which have been integrated into the SMCDA tool for site suitability analysis of MAR.

\subsection{Data types}

For MAR site selection, different types of data are required. Considerations for data type selection derive from data availability and the objective of the analysis as dependent on each data type. Geological maps, geomorphologic maps, lineament maps (e.g. Saraf and Choudhury, 1998; Jothiprakash et al., 2003; Reddy and Pratap, 2006), slope, infiltration rate (e.g. Ghayoumian et al., 2005; Werz 
et al., 2009), lineament density, structure, fluvial and denudational geomorphology (e.g. Anbazhagan et al., 2005; Shankar and Mohan, 2005; Chowdhury et al., 2010,), soil texture (e.g. Kalantari et al., 2010; Jothiprakash et al., 2003), and land use (e.g. Brown et al., 2008; Reddy and Pratap, 2006; Ghayoumian et al., 2007) have been used to provide detailed quantification of surface characteristics. Infiltration rate, transmissivity (e.g. Ghayoumian et al., 2005; Brown et al., 2008), borehole recharge capacity, borehole abstraction capacity, and recharge retention time (Anderson et al., 2005), have been used to quantify subsurface characteristics. Groundwater quality data is usually not paid any attention as being important for site selection (Brown et al., 2008; Ghayoumian et al., 2007; Chowdhury et al., 2010), although it should be due to the nature of MAR as being often involved with water storage and recovery. In addition to surface and sub-surface characteristics, Brown et al. (2008) considered ecological status, road density, power lines, proximity to a water source, and groundwater pollution among other parameters. Wood (1980) considered the possibility of aquifer plugging. Legal aspects together with cost-benefit analyses should also rank among important considerations (O'Hare, 1986). A comprehensive combination of all of these input considerations, however, is absent from the literature of MAR project site characterization.

\subsection{Data processing}

The quantity of spatial data needed to collect, integrate and analyze for MAR project site evaluation is very large and the application of traditional data processing methods for site selection can be very complex and tedious (Anbazhagan et al., 2005). In groundwater management studies, land use suitability mapping and other geographical research, GIS and remote sensing technology have been used separately or in combination to process, integrate, and analyze spatial data (e.g. Krishnamurthy et al., 1996). Use of GIS and remote sensing is also commonly used for MAR site selection studies (e.g. Saraf and Choudhury, 1998; Brown et al., 2008; Ghayoumian et al., 2007; Werz et al., 2009). Anderson et al. (2005) used the mathematical functions implemented in GIS together with spatial analysis operations to calculate retention time and recharge capacity of an aquifer over a wide spatial distribution.

\subsection{Site suitability analysis methods}

In general, the site suitability analysis follows the path: screening of feasible areas $\rightarrow$ classification of thematic layers $\rightarrow$ weighting of the criteria $\rightarrow$ overlaying.

Only few studies have concentrated on screening-out the areas where MAR is actually non-feasible (e.g. Anane et al., 2008; Brown et al., 2008; Ghayoumian et al., 2007). Boolean logic is usually used to demarcate feasible and non-feasible areas. Studies mostly concentrate on classifying maps according to relative importance. Each thematic map is classified according to importance of the respectively represented parameters. Linguistic classifiers, such as very good, good, suitable, etc. (e.g. Jothiprakash et al., 2003; Ghayoumian et al., 2005) and value type classifiers such as class 1 to class 4 are implemented in these studies (e.g. Ghayoumian et al., 2007). Step-wise functions are used in different studies in order to standardize thematic maps for aggregation. Ghayoumian et al. (2007) uses membership functions for map standardization. No linear or piece-wise linear function is used in any study for MAR site selection.

Weighting of each criterion is an important factor for spatial multi-criteria analysis. Direct weighting after consultation with experts has mostly been used (e.g. Saraf and Choudhury, 1998;
Brown et al., 2008). The Analytical Hierarchy Process (AHP), introduced by Saaty (1980), has been recently used by Chowdhury et al. (2010). The advantage of AHP in site selection or spatial multi-criteria analysis is well established (e.g. Jun, 2000; Sharifi et al., 2006) and is therefore implemented in the new tool presented in this report (see section 3.3 B).

The most important step for site selection is map overlay. Conventional overlay methods (e.g. Weighted Linear Combination (WLC)) have been practiced in most of the studies for MAR site selection (e.g. Saraf and Choudhury, 1998). Kallali et al. (2007) used Boolean logic for combining maps. Normal successive intersection of the thematic maps has been used, too (e.g. Jothiprakash et al., 2003). The Ordered Weighted Averaging (OWA) method has not been implemented in any study. It is important to note that combination of AHP-WLC or AHP-OWA has yet to be implemented and is thus presented for the first time in this report (see Chapter 3). Ghayoumian et al. (2005) briefly mentioned the integration of DSS and GIS for MAR site selection, but no special considerations for DSS decision rules or technological descriptions were provided. A spatial knowledge-based decision analysis system for pond site selection has been reported by Shrier et al. (2008). The authors coupled spreadsheet software that facilitates rule processing, with GIS to display spatial data.

Site suitability analysis for MAR is like most other site suitability analyses, but the methods which are best applied are being applied in a unique combination. The advantage of SMCDA has not been properly and fully utilized in this field. This report presents all the data types and data processing techniques needed for MAR site assessment as well as the familiar yet unique procedure to do so. Also, MAR is a developing field but also has a long and fragmented history. This report is a breakthrough for the field of MAR in the respect that state-of-the art analysis techniques are being compiled and applied in this field and finally more work is being done to ensure the continued implementation of MAR with decreased uncertainty, as demonstrated in the entirety of this paper. This report presents for the first time an interactive non-site specific decision tool for MAR site selection.

\section{The spatial multi-criteria decision support method for site suitability analysis}

The overall methodology of the new site selection tool is shown in Fig. 1. This flowchart shows the main decision steps which are implemented for spatial analysis. In general, the entire process involves three main steps: (a) constraint mapping, (b) suitability mapping, and (c) sensitivity analysis. After preparing the constraint map, AHP is combined with WLC and OWA for the suitability mapping, which is based on standardized subcriteria. The function of AHP is threefold: (1) developing the hierarchy after the selection of criteria (2) doing a pair-wise comparison to assess criteria importance and (3) undergoing construction of the overall composite weight (global weight). Afterward, WLC or OWA operators are used for the final suitability map. These steps, following the MAR problem statement, are described in greater depth below:

\subsection{Problem statement}

In water resources management, MAR has proven to be an effective response to water scarcity problems. MAR is helpful for the recovery of groundwater levels, the improvement of groundwater quality, and for storage of water and as a barrier against salinity intrusion. The selection of suitable locations for MAR 


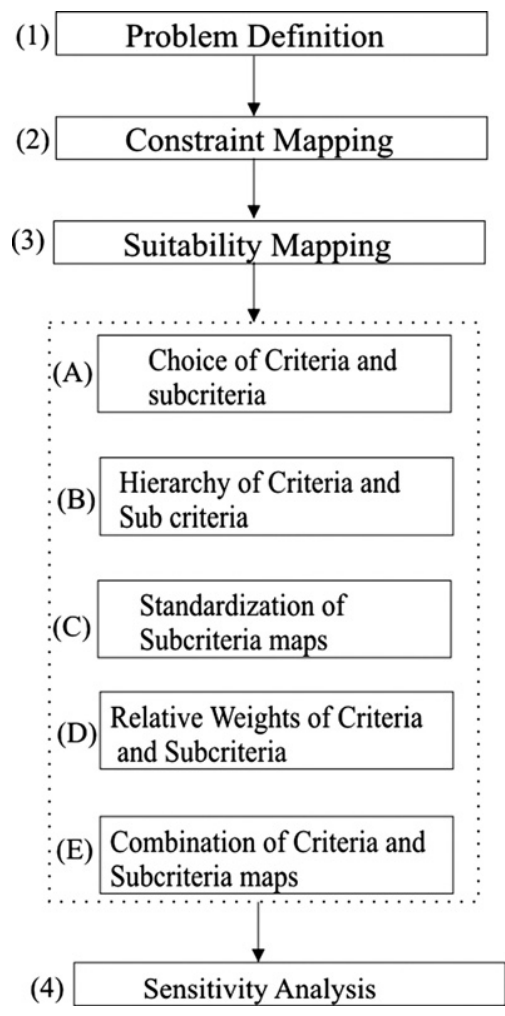

Fig. 1. The procedure for MAR site suitability mapping.

implementation based on proper technologies is one of the primary requirements.

\subsection{Constraint mapping}

The main objective of constraint mapping is to screen out a large number of alternatives which have been deemed as being non-feasible. This step helps the user to avoid conflicts in decision-making. The sites which are of prime interest to other planning projects or which are simply not available or completely non-feasible for MAR implementation are screened out in this step. A conjunctive screening approach was chosen for constraint mapping. Under conjunctive screening, an alternative is accepted if it meets specified thresholds for all evaluation criteria. Fig. 2 shows the general procedure for constraint mapping. The developed constraint map serves as a mask for suitability mapping.

\subsection{Suitability mapping}

(A) Choice of criteria and sub-criteria

In this step, all relevant surface, subsurface, and regional characteristics are selected. Each characteristic is defined as a subcriterion. The sub-criteria are grouped under the main criteria. The combined main criteria are the "suitability map," which is the goal of the SMCDA.

\section{(B) Hierarchy of criteria and sub-criteria}

The role of AHP begins at this step. This step involves the decomposition of the ultimate goal into a three-level hierarchy

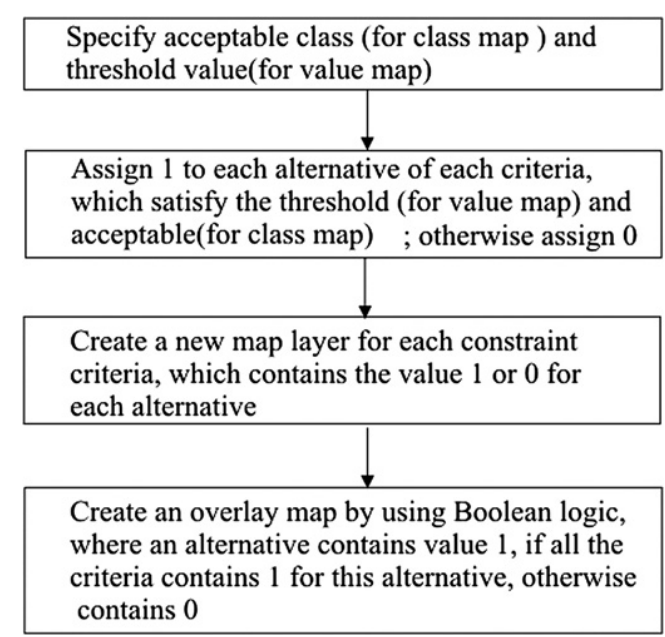

Fig. 2. Flow chart for constraint mapping.

consisting of sub-criteria of the goal. The top of the hierarchy is the goal of the analysis/problem. The middle level contains more specific criteria with regards to the objective and the bottom level refers to the most specific criteria. The sub-criteria in the lowest level are related to the main criteria in the middle level, while the top level relates to the "suitability map" (see Fig. 12). The sub-criteria are represented by thematic maps or attributes. The tool's user-interface allows the user to construct the hierarchy or "criteria tree."

\section{(C) Standardization of sub-criteria maps}

Each sub-criterion in the criteria tree is represented by a map of different types such as a classified map (e.g. land use) or a value map (e.g. slope, infiltration). For decision analysis, the values and classes of all the maps should be converted to a common scale to reduce the dimensionality. Such conversion is called standardization (Sharifi and Retsios, 2004). Different standardization methods may be applied to different maps. This model offers linear, piecewise linear, and step functions for standardization. The outcome of the function is always a value between 0 and 1 . The function is chosen in such a way that cells in a map that are highly suitable for achieving the goal obtain high standardized values and less suitable grids obtain low values.

\section{(D) Relative weights of criteria and sub-criteria}

The next step in the site selection procedure is assigning values of importance for all criteria and sub-criteria, which is done by assigning a weight to each criterion. Different weighting methods are available. Pair-wise comparison and direct weighting are used here. The sub-criteria under each main criterion are compared amongst themselves and a weight is assigned to each one. The main criteria are also evaluated in this way.

\section{(E) Combination of criteria and sub-criteria maps}

After standardization and weighting, the next step is to obtain the overall suitability index of each alternative. The index value is given to the cells of the map. Overlay methods available are WLC and OWA with fuzzy linguistic quantifiers. WLC is the most simple and the most commonly used aggregation method in spatial analysis (Eastman et al., 1993). 


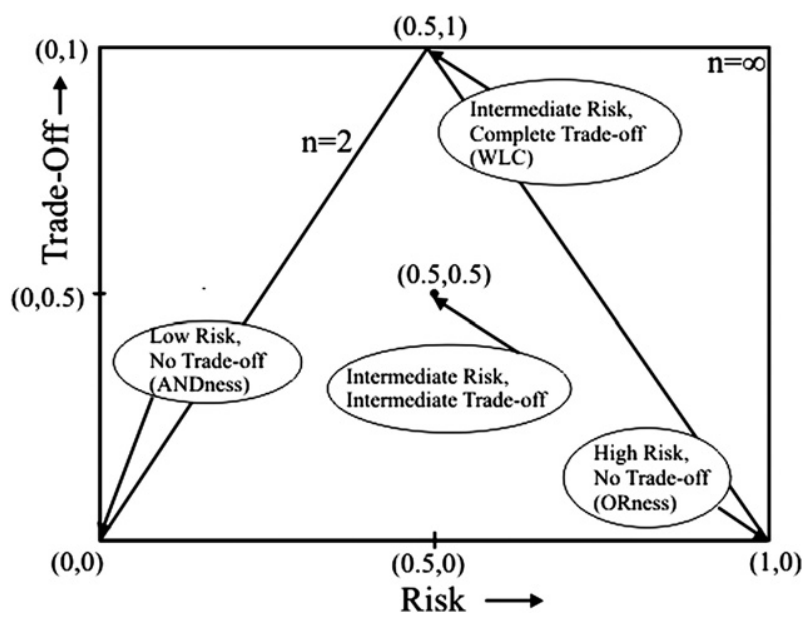

Fig. 3. The decision strategy space showing relation between trade-off and risk, $n$ is the number of criteria (modified after Eastman, 2000; Malczewski, 2006).

WLC, $\quad S\left(x_{i}\right)=\sum w_{i} \cdot s_{i}\left(x_{i}\right)$

$w_{i}=$ normalised weight; $\Sigma w_{i}=1 ; s_{i}\left(x_{i}\right)=$ standardized criteria function/map.

OWA is a class of multicriteria combination operators, involving two sets of criteria weights, which are "criteria importance weight" and "ordered weight" (Yager, 1988). The concept of fuzzy linguistic quantifiers, introduced by Zadeh (1983), allows the conversion of natural language statements into proper mathematical formulation (Munda, 1995). In this study, the regular increasing monotone quantifier class was considered. Given the criteria weights, $w_{i}$, the quantifier-guided OWA can be defined as follows (Boroushaki and Malczewski, 2008):

$\operatorname{OWA}_{(i)}=\sum_{j=1}^{n}\left(\left(\sum_{k=1}^{j} u_{k}\right)^{\alpha}-\left(\sum_{k=1}^{j-1} u_{k}\right)^{\alpha}\right) z_{i j}$

$\mathrm{z}_{i j}=$ weighted attribute value; $\alpha=$ parameter for linguistic quantifier; $u_{k}=$ criteria weight reordered according to $z_{i j} ; j=$ number of criteria.

OWA allows for a high degree of input variability and for the trade-off of importance among input variables (Fig. 3). When $\alpha=0$ (linguistic quantifier categorized as "at least one criterion satisfies"), the result yields no trade-off and full ORness; when $\alpha=\infty$ (linguistic quantifier categorized as "all criteria satisfy"), the result yields no trade-off and full ANDness. Using $\alpha$ value between 0 to $\infty$, yields a range of MCE operators in the decision strategy space. When $\alpha=1$ (linguistic quantifier is categorized as "half of the criteria satisfy"), the results yields the full trade-off (WLC) (Fig. 3).

The detailed description of AHP combination with OWA is given by Boroushaki and Malczewski (2008).

\subsection{Sensitivity analysis}

A sensitivity analysis may be undertaken by the user in order to study the robustness of the suitability map with respect to the linguistic quantifier $(\alpha)$. The new SMCDA tool also permits assessment of site suitability as respective to the influence of the application of different weighting schemes and standardization. In this respect, sensitivity analyses are useful where uncertainty exists in the construction of hierarchy and in the assignment of relative importance (Store and Kangas, 2001).

\section{GIS based site suitability analysis tool}

\subsection{Overall system framework}

The site suitability analysis tool extension is tightly integrated in the ArcMap environment. This instrument is developed as an ArcMap extension, using ArcObjects and VB.Net. ArcObjects is a developer kit for ArcGIS based on Component Object Model (COM). This solution considerably extends the functionalities of ArcMap by implementing the MCDA within the GIS environment by allowing the developer to combine the advantages given by the user interface controls available in the .Net framework with the GIS functionality included with ArcGIS (ESRI). The advantages of customized components by using a COM-Compliant environment such as Visual Studio 2005 are: (1) a wider range of functionalities can be integrated into customization, (2) codes are not accessible by the user, (3) all aspects of ArcGIS application can be used further, extended, and customized, (4) the customization can be easily supplied to the client machines (ESRI, 2004; Boroushaki and Malczewski, 2008). Fig. 4 shows the overall system development.

The model has been incorporated into the table of contents of ArcGIS as the "Site Selection" option. By activating the tab, the user can access the main steps of the site selection instruments: "Constraint Mapping," "Site Suitability Mapping," and "Site Ranking." Further options related to each main step (Fig. 5) derive from this one.

The supporting database structure is an ArcGIS Personal Geodatabase (ESRI). The geodatabase can store, beside the geographical data, data behavior rules such as domains, relationship classes, and custom behavior. The geodatabase management module is composed of two sections: (i) Data Input/Output and (ii) Spatial/ Time dependent query and visualization. The geodatabase management module focuses on designing the user screens, so these match the different sections of the data model. This component includes the following subcomponents:

- Data access subcomponent, which contains functions for database connection, data reading, and database update.

- Data model objects, which are used for storing the data in memory while the application is running. These data model

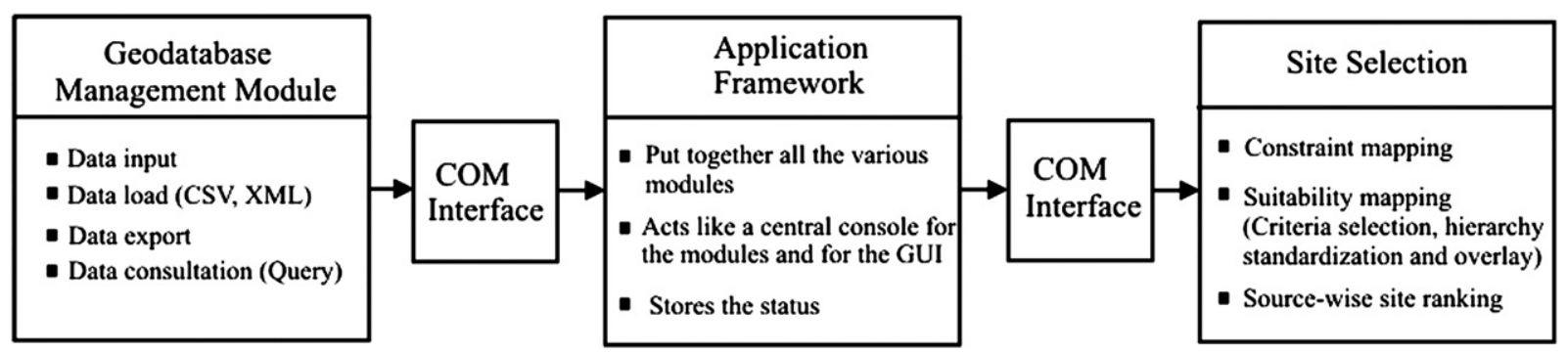

Fig. 4. Structure of the site selection tool developed in the ArcGIS environment. 


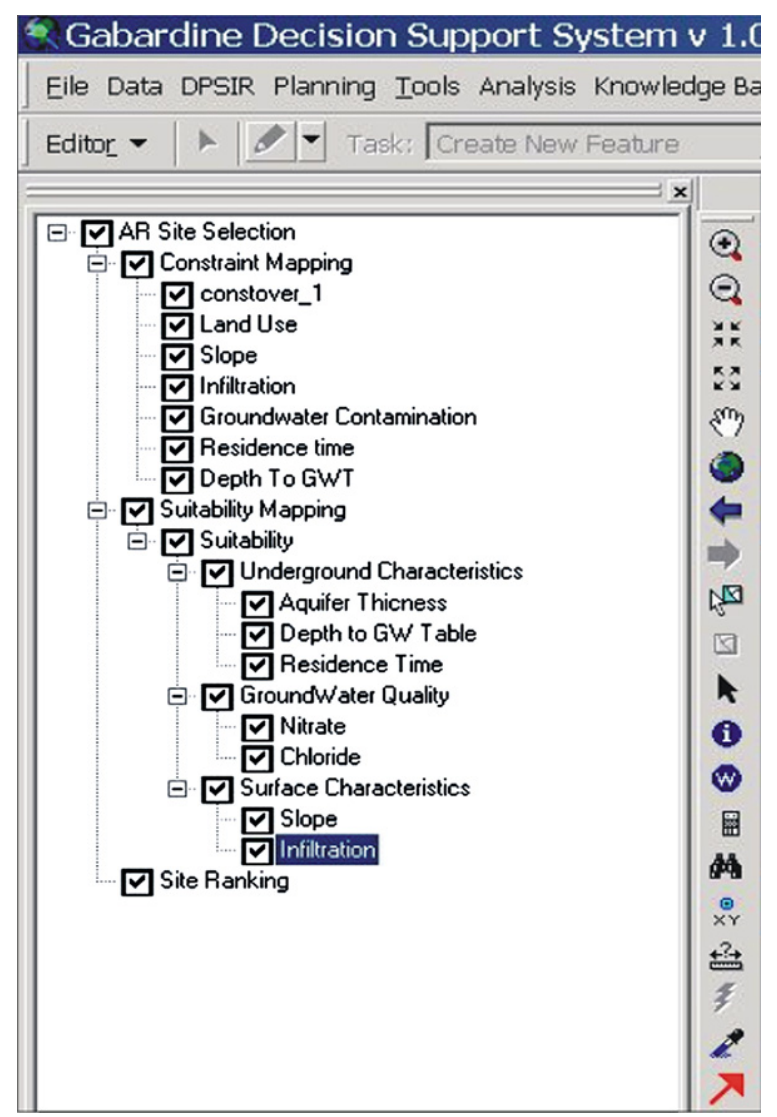

Fig. 5. Exemplary table of contents in ArcGIS Display for the site suitability analysis, incorporated to Gabardine DSS.

objects abstract the feature classes and the tables in the geodatabase and mimic the relationships between them.

- Interface components, which include the user screens that provide user access to the data stored in the data model objects. The user can input data through a list of standard user interface controls, such as text boxes, combo boxes, data grids, etc.

The personal geodatabase format was considered suitable for the scale of the current application; however, the format can be easily upgraded for further developments to an ArcSDE (ESRI) geodatabase. The ArcSDE allows connecting ArcGIS and the Site Suitability Analysis Tool interface to future database versions developed using other Spatial Relational Database Management System (RDBMS) software like Oracle, SQLServer, IBM-DB2, and others.

\subsection{Site suitability mapping}

This first step offers default criteria for choosing and selecting the corresponding raster map to generate a constraint map. The default constraint criteria have been selected after a close discussion within a consortium consisting of a number of international experts from different organisations (e.g. LNEC - National Laboratory for Civil Engineering, Portugal; University of Liege, Belgium; EWRE - Environmental \& Water Resources Engineering Limited, Israel; University of Nottingham, UK; PHG - Palestine Hydrology Group, Palestine; GeohidroConsult, Romania; University of Goettingen, Germany, etc.). Moreover, new constraint criteria may be added by the user (Fig. 6). Both value type and class type map can be handled by the system. The user defines the threshold value for value type criteria and to each class of the class type map; the user may assign a zero for a non-potential area or a one for a potential area. The system then creates a constraint map of each sub-criteria separately. Afterwards, the maps may be overlain and one constraint map may be prepared with Boolean logic. The constraint maps are added to the ArcGIS document and can be used for further analysis.

Site suitability mapping starts with the preparation of a hierarchical structure, which is performed by selecting criteria and subcriteria for each level. The user selects the criteria from the default list. The default criteria are prepared, considering all relevant characteristics that should be included for the spatial analysis. Special care has been given to avoid any duplication of the criteria/ sub-criteria. New criteria or sub-criteria can also be easily added via the user-interface. The user can visualize the hierarchical structure and edit for presentation and reporting purposes. The standardization process follows the building of hierarchy. The user selects the criteria, the constraint map, the threshold values, and the preferred standardization function. For a better visualization, the converted function is drawn graphically in the interface (Fig. 7). The overlay command of the criteria tree proceeds to the step of weighting and overlay. The system offers the pair-wise comparison and the direct weighting methods. The weights of each criterion in each level can be given directly or can be generated by the pair-wise comparison

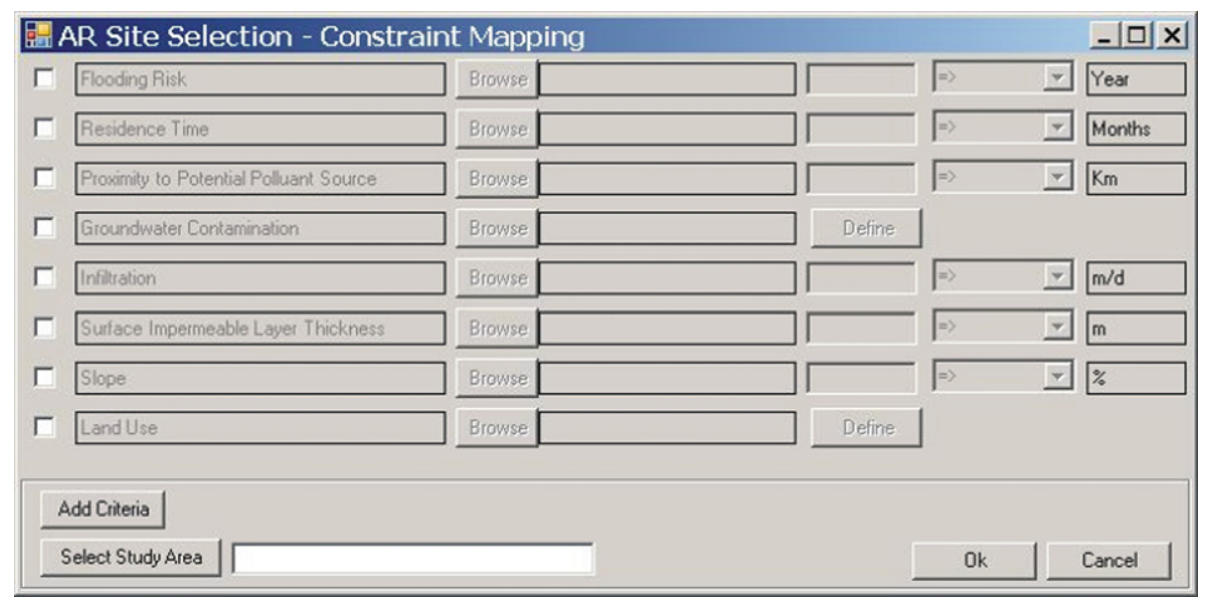

Fig. 6. Interface to select constraint criteria and assign the threshold value. 


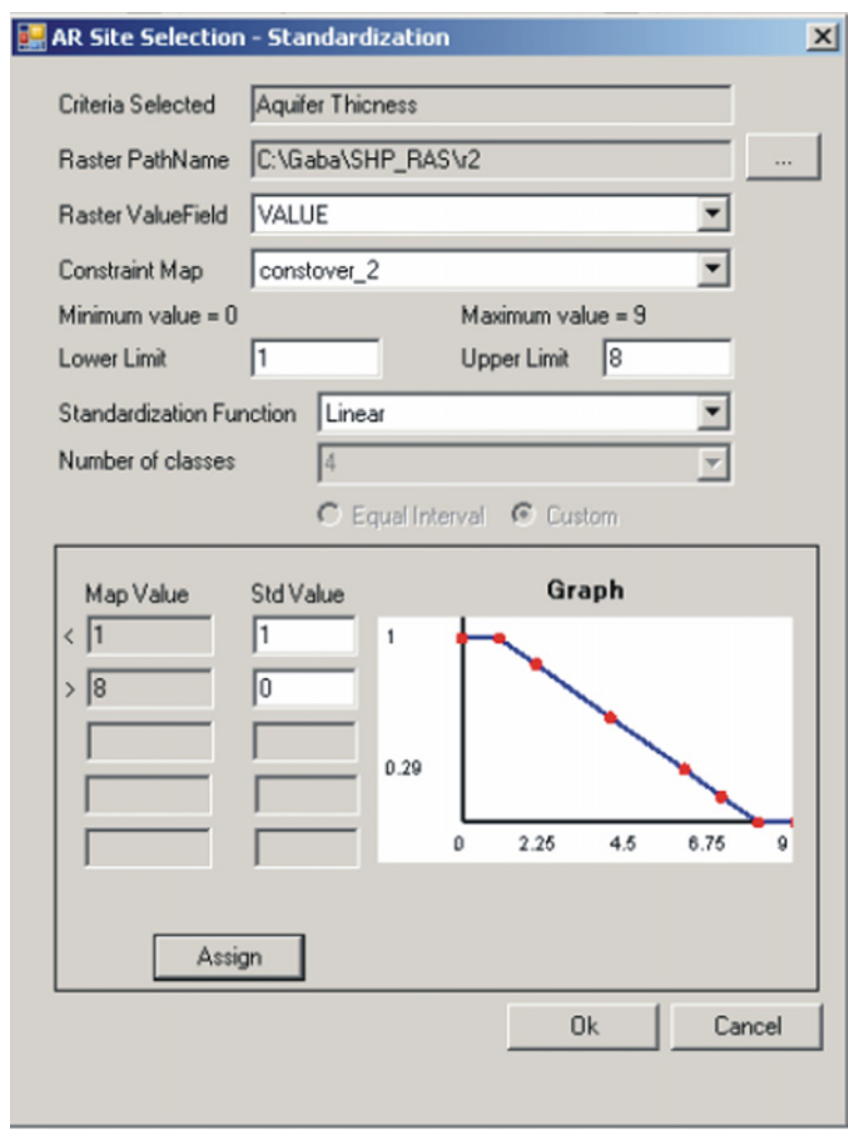

Fig. 7. Standardization procedure.

method. In the pair-wise comparison method, the user can input preferred values using a scale bar. The weights are generated using the specified formula by Saaty (1980).

After finishing the weighting procedure, the user reaches the final steps of the site suitability mapping (Fig. 8). The user chooses an overlay procedure, either WLC or OWA. In the OWA procedure, the linguistic quantifiers are assigned to each level of overlay. The resulting map is then created and shown in ArcGIS format. The role of the AHP function is the construction of a criteria tree as well as to calculate the relative weights of the criteria and of the subcriteria by pair-wise comparison. After applying the AHP, the WLC or OWA are used. WLC computes the overall suitability for each alternative or cells using the standardized map, weights, and constraint map. OWA produces the suitability maps by specifying the linguistic quantifier (a set of ordered weights are generated, which are related to $\alpha$; the generated values for each alternative are combined).

By changing the weights of each overlay method and of the linguistic quantifier associated with the objectives and attributes for OWA, a wide range of decision scenarios can be generated and the corresponding map layers are added to the map document. This helps to check the sensitivity of the system with changing weights and linguistic quantifiers.

Areas on the suitability map can be classified as very good, good, moderate, poor, and bad. The system offers five different colours for the five classes (Fig. 8), taking into account the colour code for ecological status classification proposed by the Water Framework Directive (WFD) (Water Framework Directive, 2003). The user has the opportunity to change the range of class manually.

The third step is a spatial analysis of the optimal MAR locations with respect to water source locations. In a user-defined buffer zone spatial query, the most favorable MAR locations based on proximity to water source are chosen. The result is a raster map, which shows the optimal MAR locations that satisfy the user chosen distance to proximal potential sources of water.

\section{A case study}

\subsection{Problem description}

Due to the geographical location, the Algarve region in southern Portugal is prone for experiencing droughts, and the region has been affected by many droughts over the last few decades. The hydrological year of 2004/2005 was extremely dry in the entire Portuguese mainland and especially in the Algarve region. The drought caused severe problems, considering the availability of water resources. Surface water reservoirs reached volumes that were below acceptable levels, and the Querença-Silves aquifer system was over-exploited (Fig. 9). The Querença -Silves aquifer system was a major source of drinking water to the urban areas within the Algarve region, during the 90's. Today the Funcho Dam is
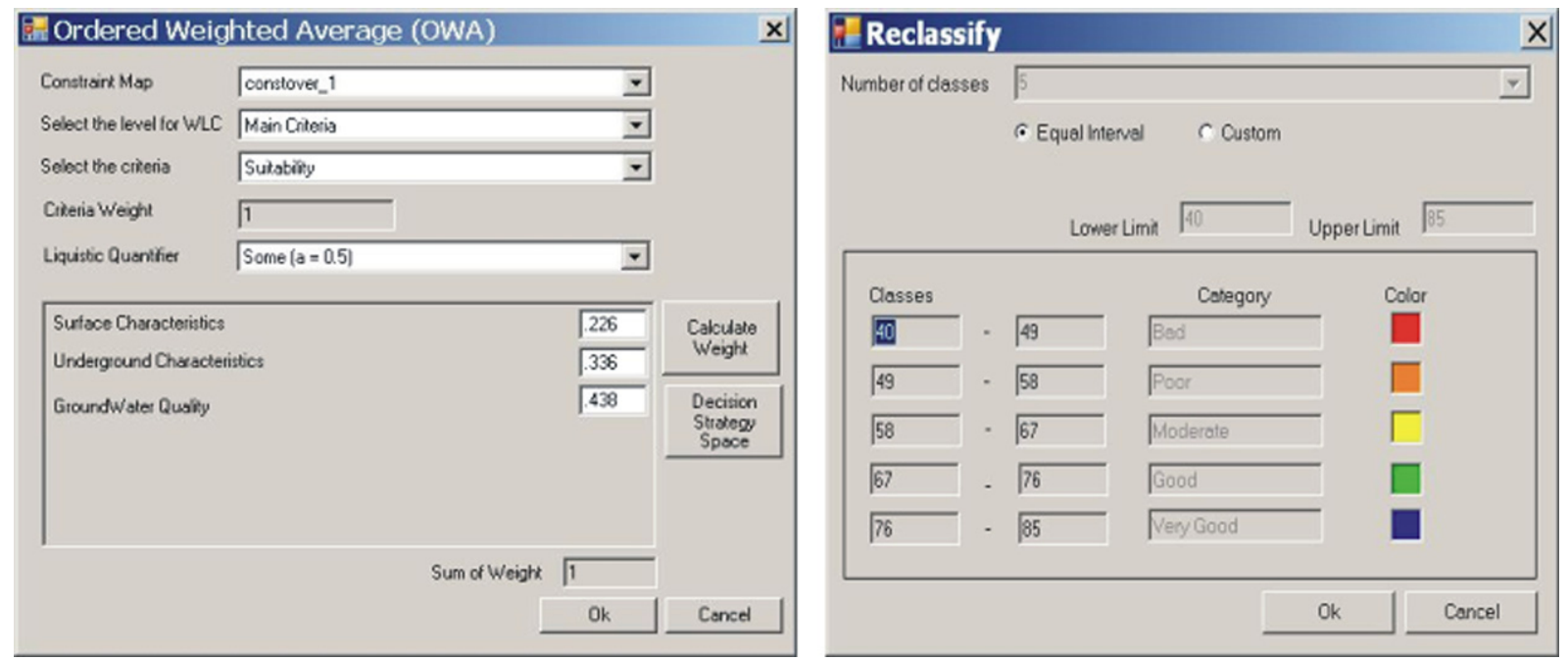

Fig. 8. The overlay for the suitability analysis (left) and the reclassification step of the suitability map (right). 


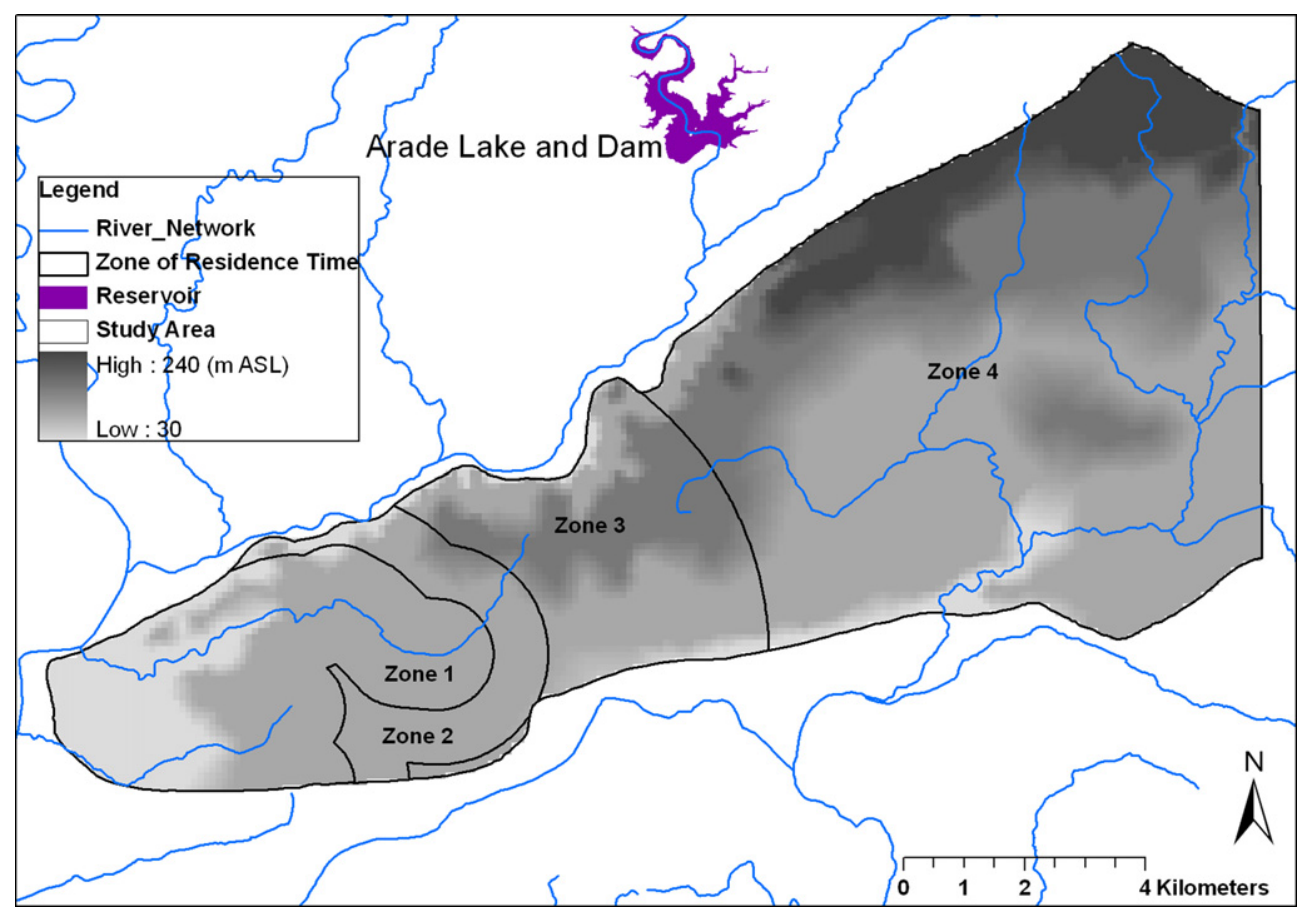

Fig. 9. Study area (Querença-Silves Aquifer) map showing the elevation (in m ASL).

considered to be the most important drinking water source in the western part of the Algarve. Another dam, the Arade Dam is located downstream of Funcho Dam in the Arade river. More than $50 \mathrm{hm}^{3}$ of river water was lost to the sea during the wet hydrological year of $2000 / 2001$, and in dry hydrological year of 2004/2005 there was an equivalent shortage of water resources $\left(54 \mathrm{hm}^{3}\right.$ ). (Lobo-Ferreira and Oliveira, 2007). MAR is considered as a potential strategy to store water during the wet years and use it during dry years. The overall planning and management of MAR consists of: selection of water source, location of infiltration basin, and location for recovery of the infiltrated water. This study focuses on suitability mapping for the implementation of infiltration ponds for aquifer recharge.

\subsection{General characteristics of the test site}

The Querença-Silves Aquifer System is a $318 \mathrm{~km}^{2}$ aquifer system, the largest of the Algarve, located in the municipalities of Silves, Loulé, Lagoa and Albufeira (Central Algarve). The aquifer is mainly composed by karstified Lower Jurassic (Lias-Dogger) dolomite structures. The southwestern part of the aquifer is mainly unconfined. The general groundwater flow direction is from Northeast to Southwest. According to the characterization of the QuerençaSilves aquifer system (Almeida et al., 2000), the hydraulic parameters are heterogeneous and aquifer productivity values are high. The transmissivity values range between 83 and $30,000 \mathrm{~m}^{2} /$ day and the storage coefficient ranges from $5 \times 10^{-3}$ to $3 \times 10^{-2}$. INAG (2001) presents the recharge value as being $220 \pm 54 \mathrm{~mm} /$ year. This represents a percentage of precipitation of around $40 \pm 10 \%$. Monteiro (2005) obtained an average recharge of $292.5 \mathrm{~mm} / \mathrm{year}$. These are average values using the average precipitation values in the area, therefore when the precipitation is much smaller (e.g. the hydrological year of $2004 / 2005$, when precipitation was more than half the average) the recharge is also much lower.

Analyzing 69 wells of the aquifer for the year 2002, a withdrawal rate of $19.5 \mathrm{~mm} /$ year was computed as being possible to meet the water demand of Silves, Lagoa, Albufeira and Loulé. This value was higher during the drought years of 2004-2005.

In this study, only the southwestern part of the Querença-Silves Aquifer is being taken into account due to geology and aquifer properties. The groundwater catchment area is $114 \mathrm{~km}^{2}$. For analysis purposes, the study area has been divided into four zones (Fig. 9), according to the residence time of groundwater in the aquifer. These are: Zone I (residence time is less than 6 months), Zone II (residence time is 6 months to 1 year), Zone III (residence time is 1 year to 3 years) and Zone IV (residence time is greater than 3 years). These zones are overlain in each constraint and suitability map so as to assess suitable MAR sites according to the residence time zonation. Results of GIS analysis and of groundwater modeling have been used as spatial input information for MAR site selection procedure.

\subsection{Selection of criteria for spatial analysis}

After discussion with local and international experts and institutions and under the prevailing site characteristics and study objectives, two different sets of criteria were selected: a) criteria for constraint mapping and b) criteria for suitability mapping. Some important criteria were selected for both cases after analyzing their importance and relevance. Table 1 lists the selected criteria for constraint and suitability mapping, showing the relevance and the usefulness of each criterion for MAR site suitability mapping.

\subsection{Constraint mapping}

In order to screen out the non-feasible areas, constraint mapping was undertaken at an early stage. Table 2 shows the list of criteria and their threshold values for screening. For the land use map, land class feasibility was defined separately (Table 3). The threshold values for each constraint criteria are chosen so that criteria values or classes should satisfy the minimum requirement of MAR implementation such as the infiltration basin 
Table 1

List of criteria chosen for constraint mapping and suitability mapping and their relevance to MAR site selection.

\begin{tabular}{|c|c|c|}
\hline Criteria & In the model, used for & Description \\
\hline Land use & Constraint mapping & $\begin{array}{l}\text { The existing land use provides information about the land availability for MAR. } \\
\text { For example, areas that are under commercial and industrial use, are non-feasible } \\
\text { areas for MAR implementation. }\end{array}$ \\
\hline Slope (topography) & $\begin{array}{l}\text { Constraint mapping and } \\
\text { Suitability mapping }\end{array}$ & $\begin{array}{l}\text { Steeper slopes do not permit the implementation of infiltration basins. } \\
\text { Furthermore, water runoff is directly related to slope angle. Flat areas } \\
\text { allow high infiltration rates and is suitable for aquifer recharge. } \\
\text { The lower the value, the higher the priority. }\end{array}$ \\
\hline Infiltration rate (soil) & $\begin{array}{l}\text { Constraint mapping and } \\
\text { suitability mapping }\end{array}$ & $\begin{array}{l}\text { Infiltration rate of soil controls the penetration of surface water into an } \\
\text { aquifer system. Soils with high infiltration capacity are more suitable than } \\
\text { those of low infiltration capacity. }\end{array}$ \\
\hline Sub-surface impermeable layer thickness & $\begin{array}{l}\text { Constraint mapping and } \\
\text { suitability mapping }\end{array}$ & $\begin{array}{l}\text { The thickness of impermeable layer should not be high, otherwise the excavation } \\
\text { costs would be high. The lower the value, the more suitable the place. }\end{array}$ \\
\hline Groundwater depth & $\begin{array}{l}\text { Constraint mapping and } \\
\text { suitability mapping }\end{array}$ & $\begin{array}{l}\text { In terms of water quality improvement by natural attenuation processes, } \\
\text { considerable unsaturated zone thickness is preferred. A deeper groundwater } \\
\text { level benefits of the natural attenuation capacity at the studied location. }\end{array}$ \\
\hline Distance to groundwater pollution source & Constraint mapping & The place of MAR should have a sufficient distance from groundwater pollution sources. \\
\hline Aquifer thickness & Suitability mapping & $\begin{array}{l}\text { Suitable sites should have high thickness values. Transmissivity and aquifer storage } \\
\text { volume depends on the aquifer thickness. The higher the value, the higher the priority. }\end{array}$ \\
\hline GW quality (chloride and nitrate) & Suitability mapping & $\begin{array}{l}\text { The groundwater quality should be adequate at the place of recharge, except the } \\
\text { objective of the MAR is to improve the groundwater quality. The parameter } \\
\text { has to be considered function of the groundwater quality of the area. }\end{array}$ \\
\hline Residence time & $\begin{array}{l}\text { Constraint mapping and } \\
\text { suitability mapping }\end{array}$ & $\begin{array}{l}\text { The residence time of the infiltrated water in the aquifer should be sufficient } \\
\text { to be able to use the aquifer as water transfer and recovery system. }\end{array}$ \\
\hline
\end{tabular}

construction, the water quality improvement by using unsaturated zone, the aquifer storage capacity and others. For example, the used threshold value for the residence time of 6 months, as mentioned by most of the international standard guidelines for MAR (CDPH, 2008; NRMMC, EPHC, NHMRC, 2009) suggest to keep the water in the aquifer at least 6 months for water quality improvement.

After defining the threshold values for each criterion, the thematic map of each constraint criterion has been converted to a constraint map. Fig. 10 shows the thematic map of slope and the converted constraint map. All the converted thematic maps were overlain by conjunctive screening to achieve the final constraint map (Fig. 11). This constraint map was used later as a mask for suitability mapping.

\subsection{Suitability mapping}

After analyzing all available data and site characteristics, subcriteria were selected according to their characteristics, and the main hierarchical structure was prepared (Fig. 12). The sub-criteria, or thematic layers, were standardized. Three value functions, such as linear, piece-wise linear, and step-wise linear functions were used for this approach (Fig. 13).

The importance of each sub-criterion has been calculated using pair-wise comparisons and this is shown in Fig. 12. Infiltration rate of the soil, residence time of groundwater, and depth to groundwater were given highest priority in the analysis. Groundwater quality was a low priority criterion because of low variability of groundwater quality over the entire area. The weighted criteria were then overlaid by two state-of-the-art overlay procedures: WLC and OWA.

Fig. 15 shows the suitable sites for MAR in the region using the WLC method. Fig. 16 shows suitability maps using the OWA procedure. The map shows the suitable places under the following decision condition: "half" of the important criteria are satisfied by an acceptable alternative. According to the definition of the OWA, when $\alpha=1$, the output should comply with the WLC output.

\subsection{Sensitivity analysis}

A sensitivity analysis was done which indicates a significant change in site suitability based on changes in risk acceptance of

Table 2

Defined threshold values (discarding conditions) of the selected criteria for MAR constraint mapping.

\begin{tabular}{lll}
\hline Criteria name & Threshold value & Explanation \\
\hline Land use & - & See Table 3. \\
Infiltration rate (soil) & $25 \mathrm{~cm} /$ day & The areas where infiltration rate is greater than $25 \mathrm{~cm} /$ day are considered as potential area. \\
Groundwater depth & $5 \mathrm{~m}$ & The places where groundwater depth is greater than $5 \mathrm{~m}$ are considered as potential sites. \\
GW pollution sources & $500 \mathrm{~m}$ & The places which are within the radius of $500 \mathrm{~m}$ of groundwater pollution sources are rejected. \\
Residence time & $6 \mathrm{months}$ & A residence time of at least 6 months should be guaranteed. \\
Slope (topography) & $5 \%$ & MAR is feasible for areas with less than $5 \%$ slope. \\
\hline
\end{tabular}

Table 3

Categorization of the land use types at the study area for MAR constraint mapping.

\begin{tabular}{ll}
\hline Land use type & Threshold \\
\hline Agricultural systems, agricultural areas outside irrigation perimeters, irrigated areas, quarries/stone pits, & Non-feasible (value is 0) \\
marshy places, salt-pits, isolated urban areas & \\
Permanent crops, orchards, poor pastures/grasslands, natural vegetation, underwood, rivers & Feasible (value is 1) \\
(water in lines to build check dams, and infiltrate) & \\
\hline
\end{tabular}


a

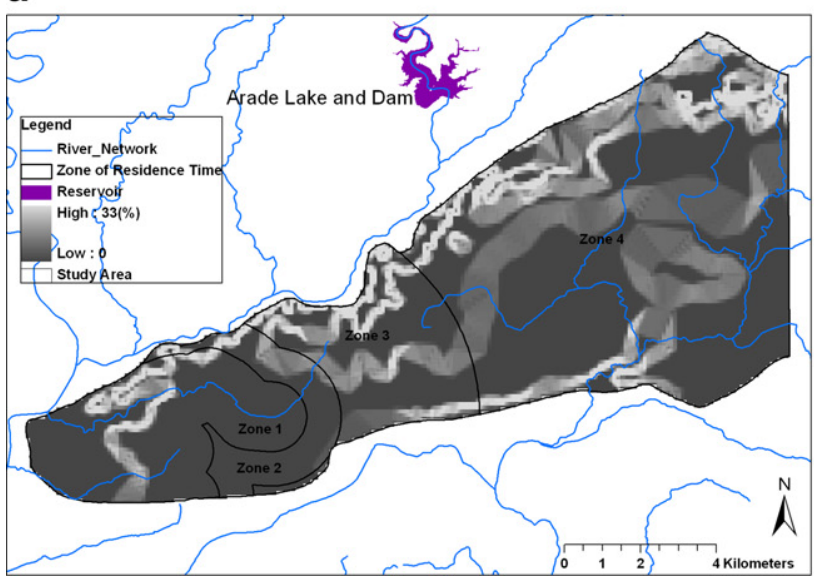

b

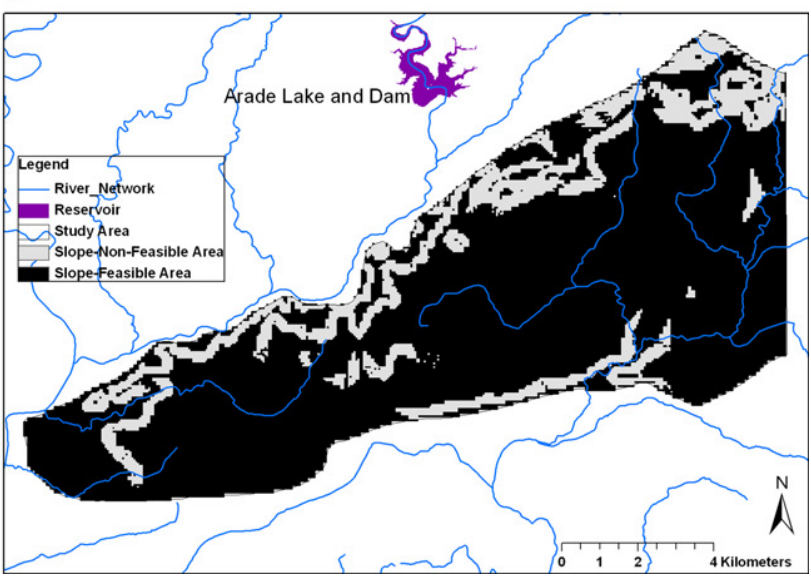

Fig. 10. Thematic map of slope (left) and it's converted constraint map (right).

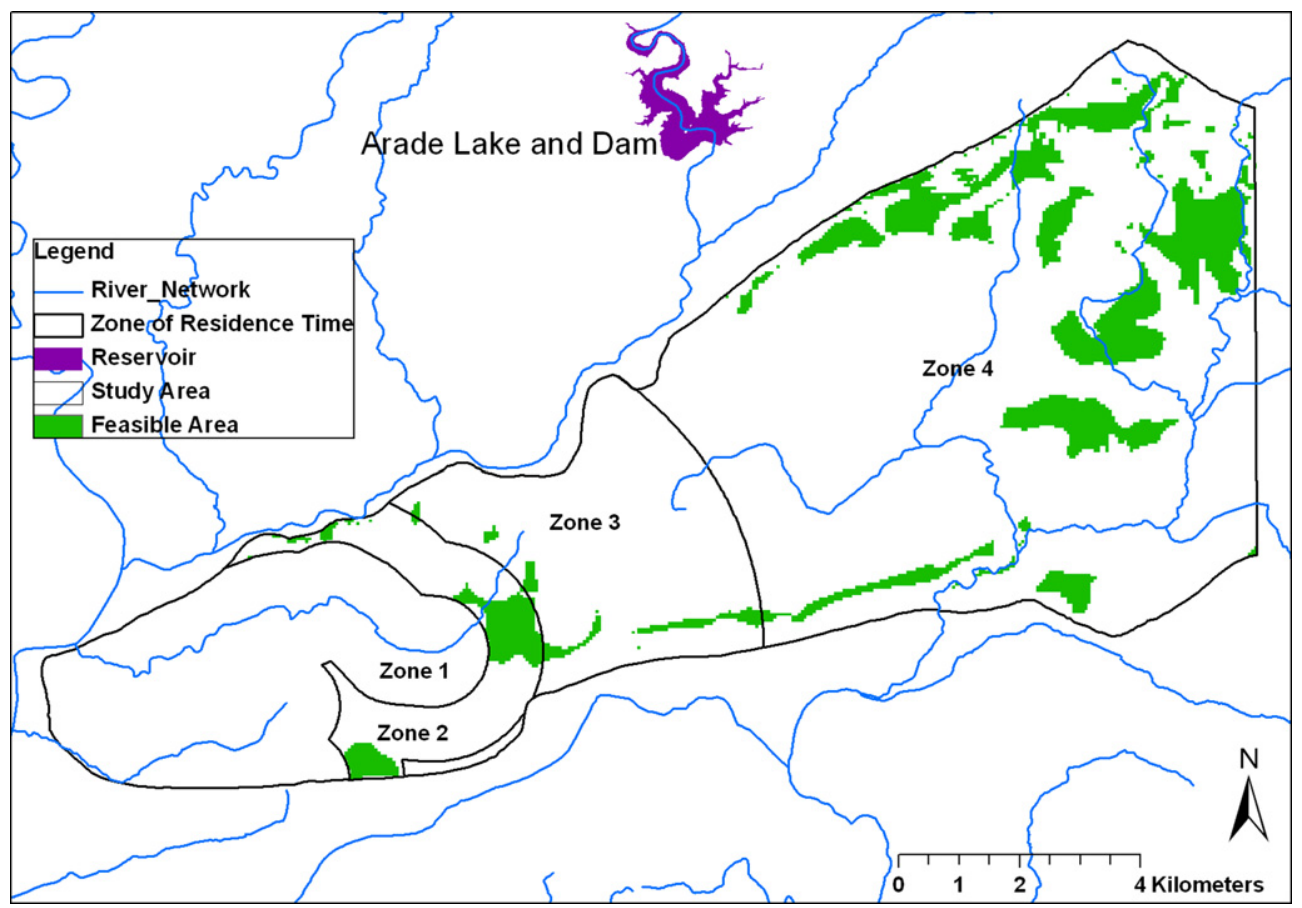

Fig. 11. Constraint map for suitability mapping.

the decision maker (see details in Fig. 3). In this way, different decision maker's attitudes may be simulated and considered in the MAR planning process, contributing to the integrated management of water resources. A sensitivity analysis has been performed to demonstrate the effect of the decision rules on the site selection procedure. Given the standardized map and corresponding criterion weight, we have chosen four fuzzy linguistic quantifiers: at least a few $(\alpha=0.1)$, a few $(\alpha=0.5)$, most $(\alpha=2)$

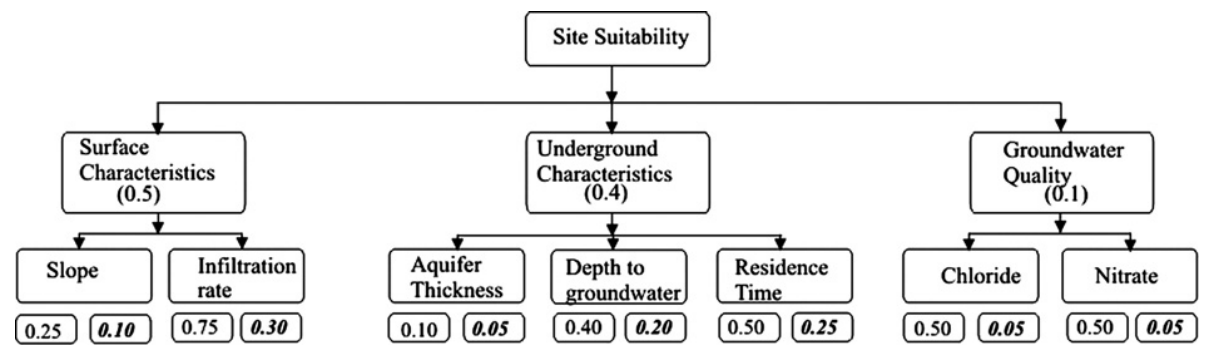

Fig. 12. Criteria for suitability mapping and hierarchical structure (in brackets the local and global weights are given). 

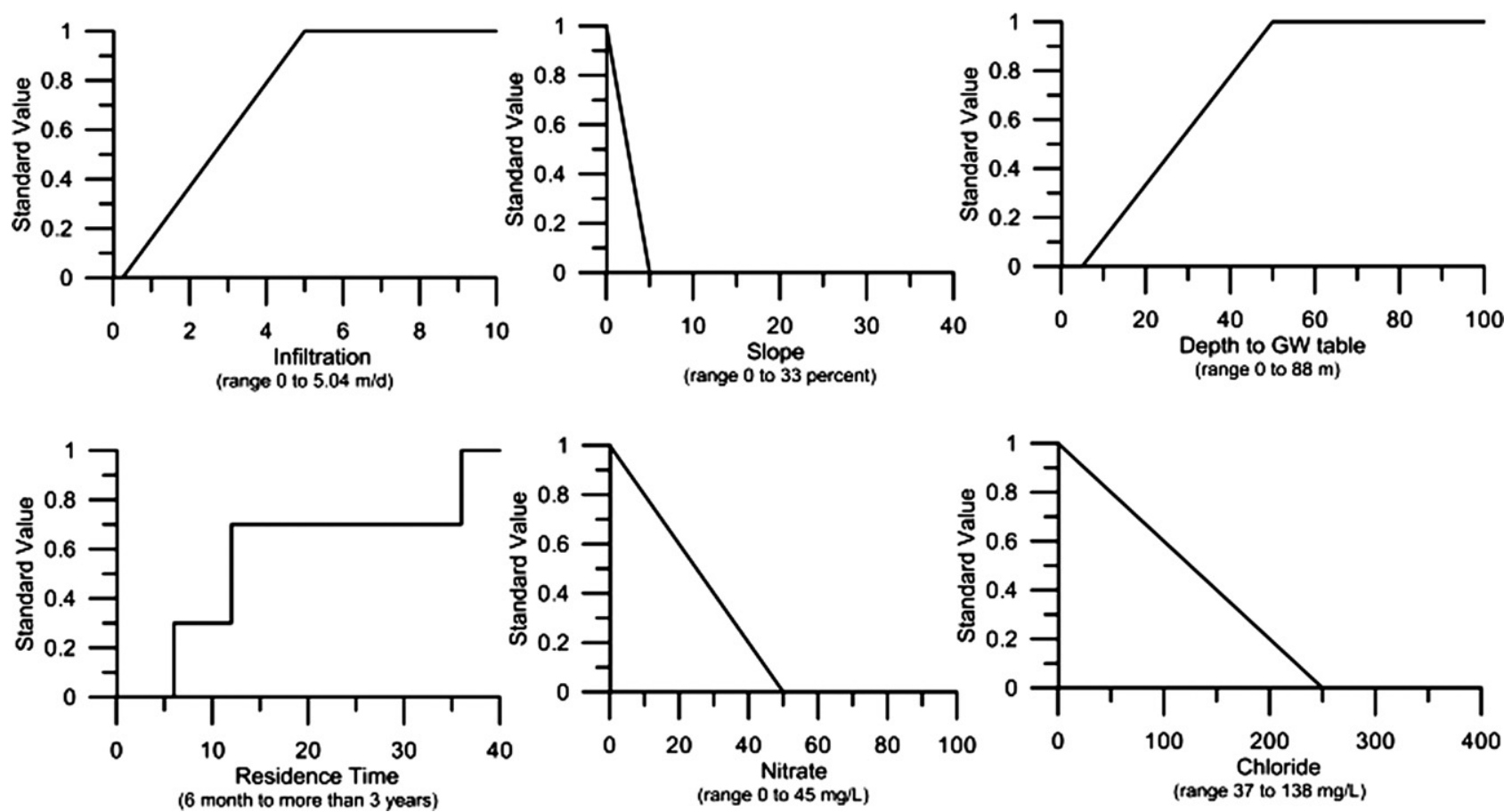

Fig. 13. Procedure for criteria standardization used in this study (range indicates the limit of the criteria value present in the study area).

and almost all $(\alpha=10)$. The corresponding OWA maps are shown in Fig. 17.

\subsection{Results and discussion}

The constraint map (Fig. 11) generated by the Boolean logic overlay method shows that only $11.2 \%$ of the total study area is feasible for construction of infiltration ponds to recharge groundwater. Land use and infiltration capacity of the soil are the main constraints for the potential site selection. Most of the potential sites are located in Zone 4, which is characterized by a higher groundwater residence time. The overall suitability map shows the relative ranking of the potential sites, generated by constraint mapping, according to the criteria importance. The suitability scores indicate the relative site ranking alternative to construct an infiltration basin. High suitability scores indicate the site is highly suitable for MAR. It is evident from the suitability analysis (Fig. 14) that considering only surface characteristics, the study area offers just few adequate locations for the implementation of infiltration basins. In contrast to that, the study shows good suitability for aquifer recharge with regards to the generally feasible areas, considering the prevailing underground characteristics. According to the overall suitability score (Figs. 15 and 16$) 1 \%$ of the total aquifer is very good (suitability score $80-100$ ), $3.2 \%$ is good (suitability score $60-80$ ), $6.4 \%$ is moderate (suitability score $40-60$ ), and $0.6 \%$ is poor for MAR. The rest $88.8 \%$ of the aquifer surface is not suitable at all due to the constraints of MAR implementation. The most suitable areas are situated on agricultural land which have high infiltration capacity soil (infiltration rate ranges between $2.7 \mathrm{~m} / \mathrm{d}$ and $5 \mathrm{~m} / \mathrm{d}$ ) with very flat topography (slope is about $0 \%$ ), and which do not require additional excavation efforts. The groundwater table under the agricultural land is at about $70 \mathrm{~m}$ below the land surface, which provides a sufficient unsaturated zone thickness to assure the a

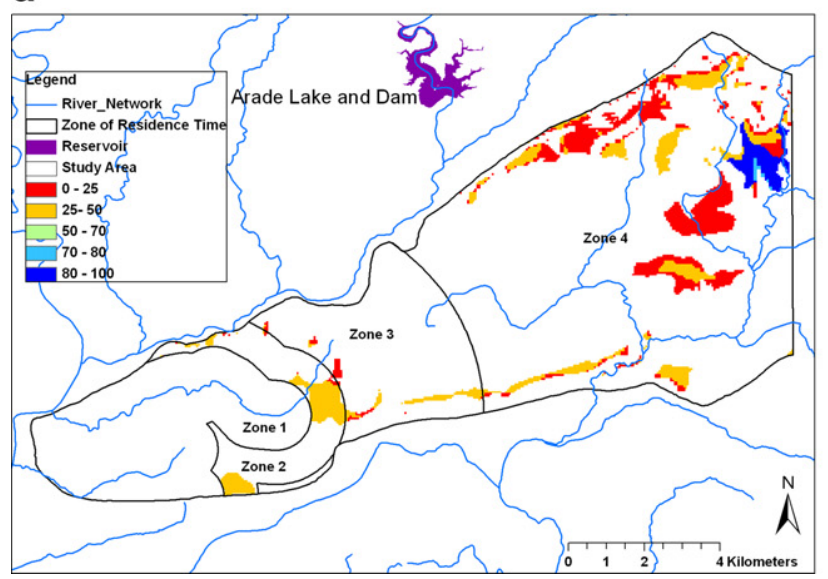

b

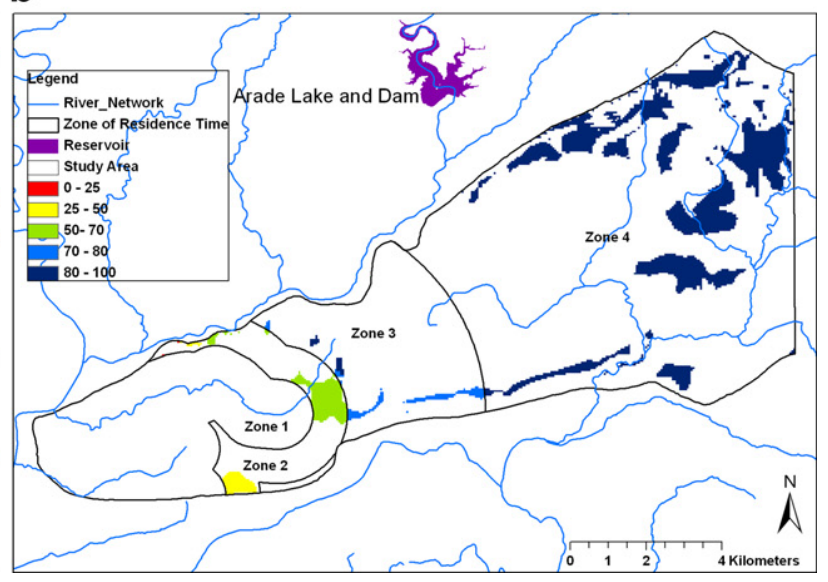

Fig. 14. Weighted Linear Combination map for considering surface characteristics (left) and underground characteristics (right). 


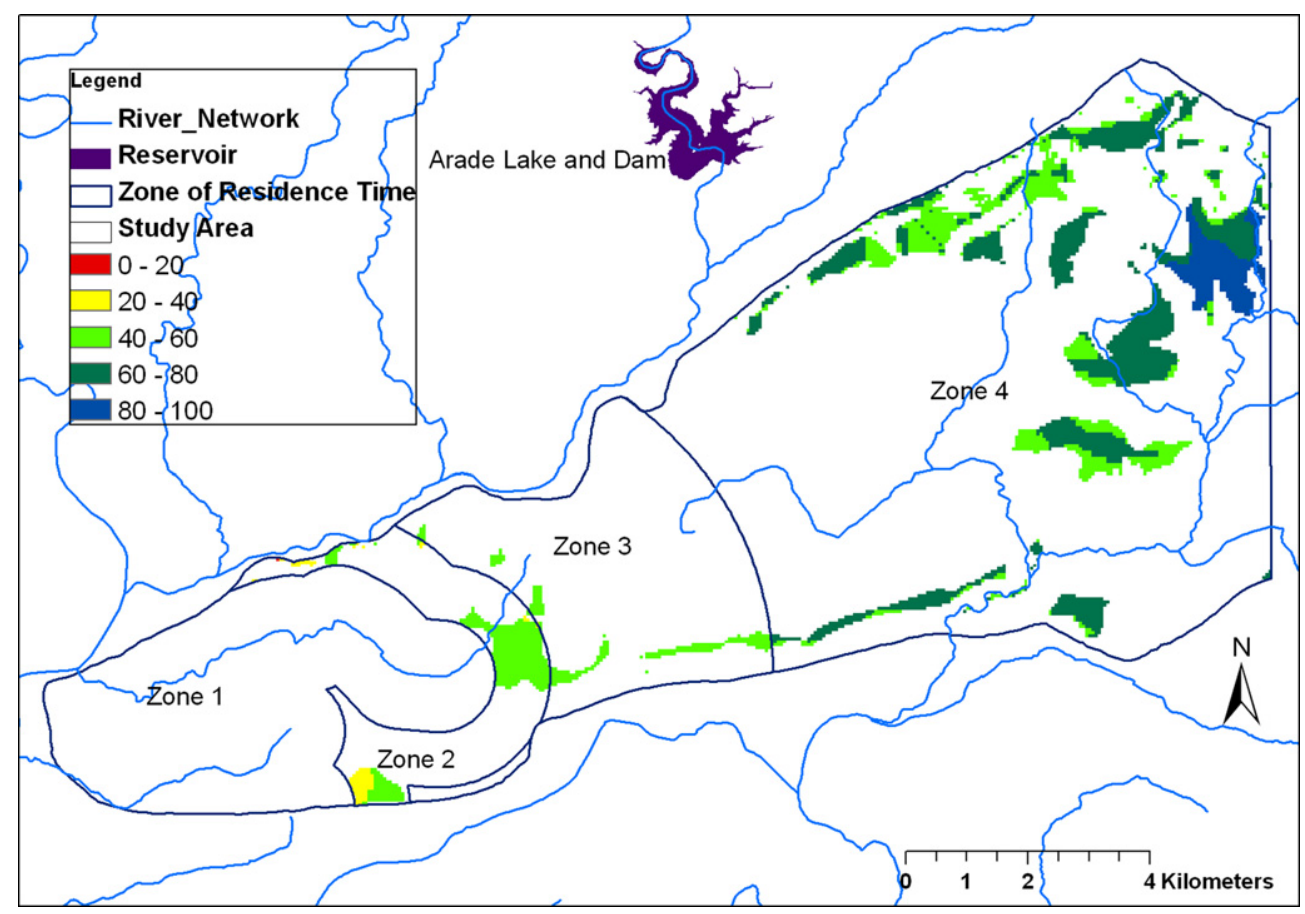

Fig. 15. Site suitability for MAR based on Weighted Linear Combination (WLC).

water quality improvement. The groundwater quality is moderate at the high suitability scores places. Since the regional groundwater flow direction is northeast to southwest, the infiltrated water may be easily transferred downstream from the highly suitable area to the northeastern part of the study area by using the natural groundwater flow. The water may then be pumped in Zones 1 and 2 where drinking water pumping wells are already installed. The distance to the Arade Dam, the potential water source for MAR, is at about $8.5 \mathrm{~km}$ distance from the highly suitable areas. This distance may incur extra water transportation costs. An approximately 27 ha area is categorized as "Good" which is at only $3 \mathrm{~km}$ distance from the Arade Dam. The groundwater is at about $60 \mathrm{~m}$ depth and its quality is moderate. In this location the infiltration rate is relatively low. In this area a comparative study and a pilot experiment is desirable in order to make the final decision of using an infiltration basin.

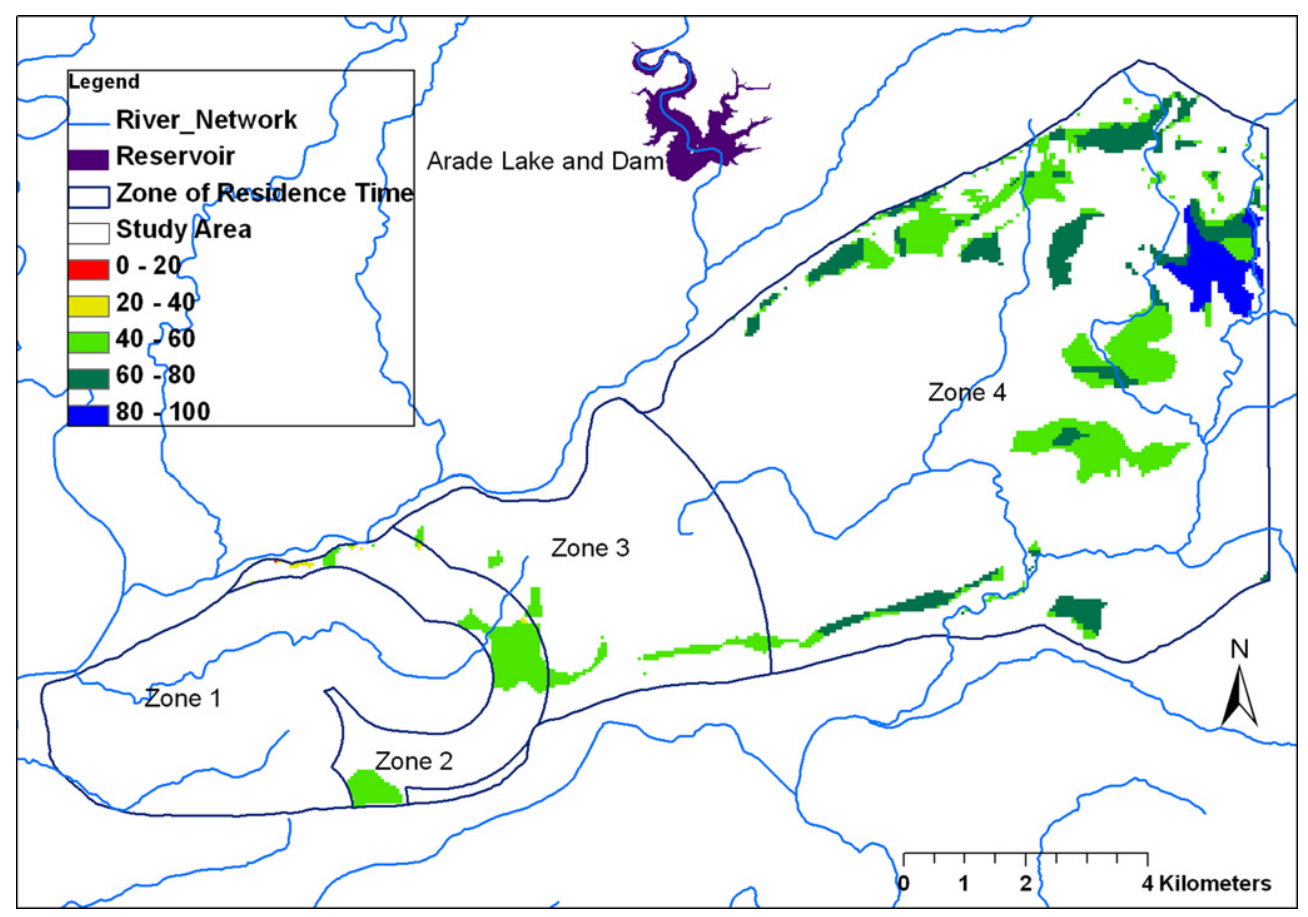

Fig. 16. Site suitability map using Ordered Weighting Average (OWA) method, $\alpha=1$ decision rule. The assigned $\alpha$ value corresponds to each level of the hierarchy. 
a

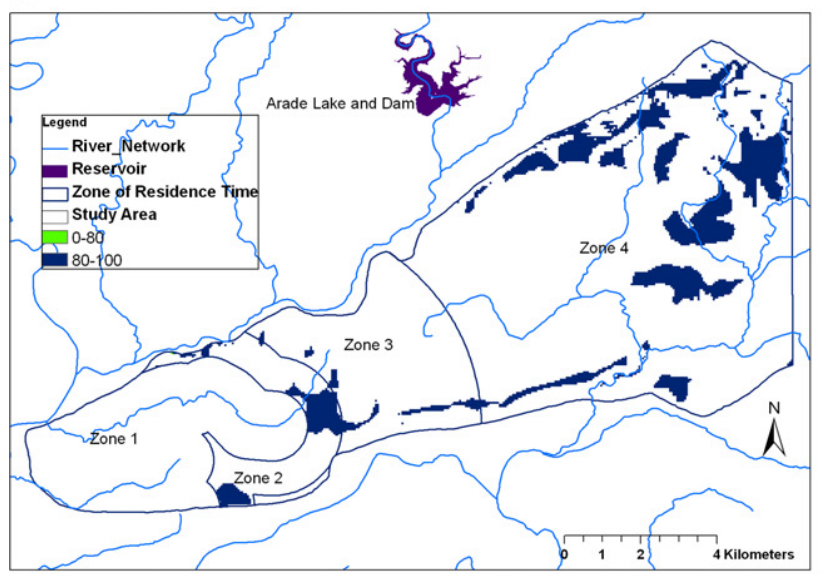

C

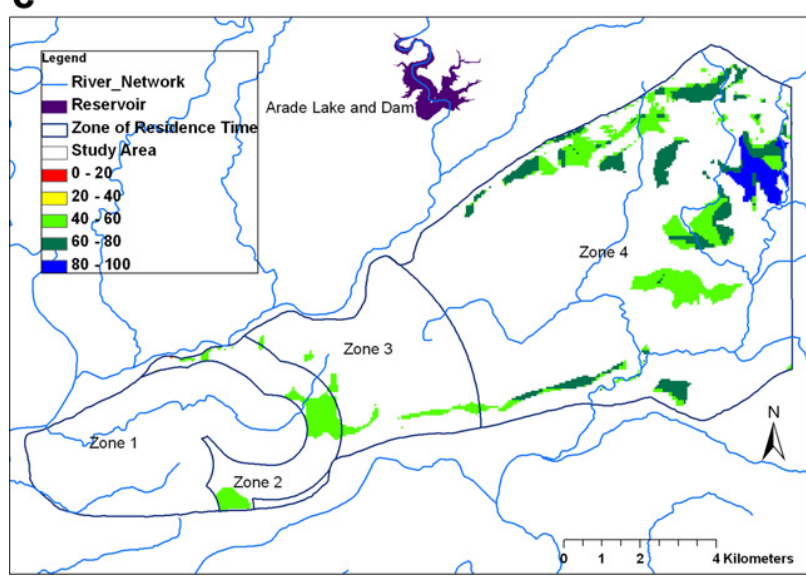

b

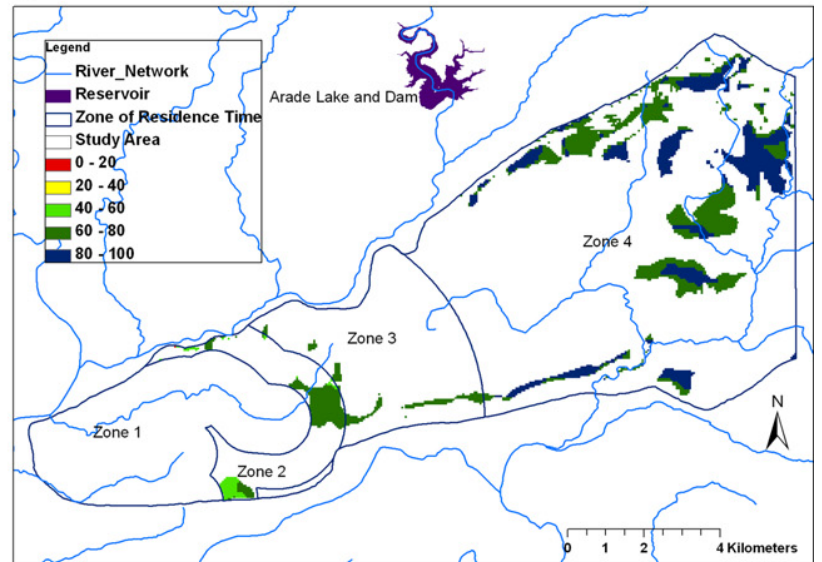

d

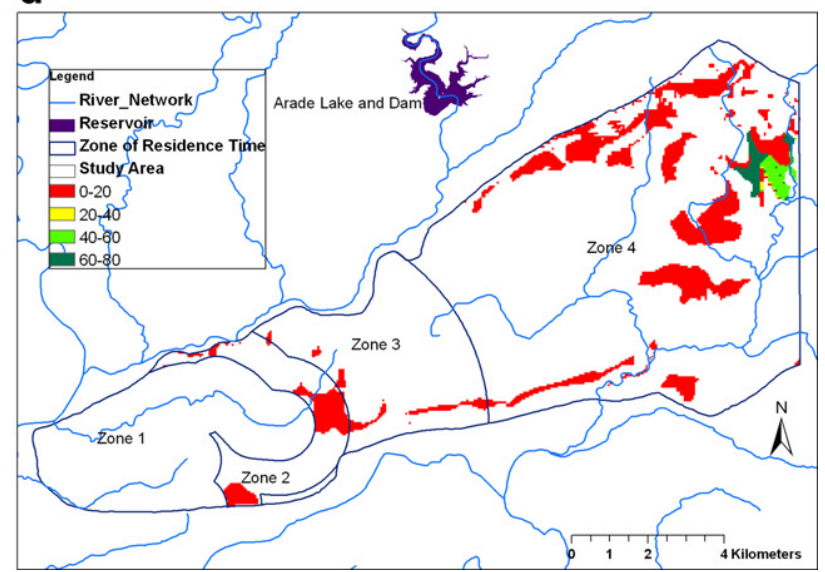

Fig. 17. Sensitivity analysis showing the change of site suitability according to the change of decision rule; the assigned $\alpha$ value corresponds to each level of the hierarchy for each performed analysis. (a. upper left) $\alpha=0.1$; (b. upper right) $\alpha=0.5$; (c. lower left) $\alpha=2$; (d. lower right) $\alpha=10$.

The sensitivity analysis indicates a change in site suitability due to varying risk acceptance of the decision maker (Fig. 3). In this way, different decision makers' attitudes have been simulated and may be considered in the MAR planning process. This unique capability of the new SMCDA tool contributes to its better integration in various water resources management activities The sensitivity analysis (Fig. 17) indicates also the significant impact of the decision rules on site suitability mapping. The first map of Fig. 17(a) indicates the best solution of site suitability. This represent the most optimistic decision strategy (at least a few criteria should satisfy) of the decision maker. In this case, almost the entire feasible area $(10.8 \%$ of the total area) falls into the category "very good." When increasing the value of $\alpha$ (or reducing the risk), the number of suitable areas which are categorized as "very good" is reduced. The last map (Fig. 17d) shows the worst-case scenario when the decision rules are considered. In this case (almost all criteria should satisfy), no place is categorized as being "very good," but $9.7 \%$ of the total area is categorized as being "bad." From the four alternative maps presented in Fig. 17 together with the map presented in Fig. 16, one may notice that the fuzzy quantifier based on OWA approach is able to simulate a wide range of decision maker's preferences regarding MAR implementation.

\section{Conclusions and recommendations}

This paper mainly demonstrates the new suggested GIS based spatial multi-criteria decision analysis software tool for the site ranking to implement MAR projects. Site selection analysis involves a number of criteria, alternatives and decision factors, resulting in a complex decision environment. With this new tool, the decision steps are explicitly given to the user according to the overall analysis procedure in order to tackle an unstructured problem. Standard criteria and decision rules are offered to the user in order to reduce the analysis efforts and the risk of ignoring relevant decision criteria. The considered hierarchical framework of AHP promotes clear thinking and better understanding of the problem together with reducing errors in importance judgment. Pair-wise comparison permits the checking of consistency to the user's input weight. Decision makers are able to obtain a wide range of decision strategies and scenarios by changing linguistic quantifiers, in the incorporated OWA method (Yager, 1988). In order to show the efficiency of the tool, a case study has been performed in Querença Silves Aquifer, Portugal. Provided default criteria, explicit decision steps, and flexibility in varying criteria standardization and overlay, are found to be very beneficial.

According to the analysis results from the case study, there are just few areas, $11.2 \%$ of the total aquifer, where the implementation of infiltration ponds would be feasible. Non-adequate surface characteristics cause further restrictions for MAR implementation. On the contrary, the underground characteristics, studied for the feasible areas, are adequate for the MAR implementation by means of infiltration technologies. The overall suitability maps, in both methods, suggest installing the infiltration ponds in Zone 4. The high suitability areas are characterized by adequate unsaturated 
zone thickness, which is very important for water quality improvement. The groundwater quality is also moderate. In order to obtain more locations for infiltration ponds, better analysis of restrictions with regards to land use and soil type is recommended. Decisions with regards to the selection of optimal locations for the installation of water recovery wells and groundwater protection should be supported by groundwater flow and transport modeling, while checking the actual flow path of the infiltrated water and the impact of water pollution sources. Besides this, some other insitu parameters, such as soil salinity, organic carbon content, and sediment chemistry can be studied further in order to rank the alternatives according to the potential of further water quality improvement. Some socio-economic criteria, recharge and recovery water transportation cost, cost of excavation, etc. can be taken into consideration for further study. Above all, the local agency can verify the analysis result while implementing MAR on the test site.

The SMCDA tool can be further developed to support more decision analysis techniques for the end user. In the future, a number of standardization functions (e.g., concave, convex, sigmoidal functions etc), weighting methods (such as ranking method, rating method etc.), and overlay methods (e.g., fuzzy additive weighting method, composite programming etc,), will be added to the existing SMCDA tool. The new spatial multicriteria analysis tool, due to its non-site specific, adaptive and comprehensive concept may serve as a complementary element for any GIS based Water Resources Management support system. By altering the input criteria and using the relevant dataset and decision rules, this spatial multicriteria analysis tool can be applied to a wide range of disciplines, such as groundwater vulnerability assessment, land use planning, site selection for waste disposal etc. Multi-objective decision analysis techniques can be added to this tool easily. The tool has been already implemented in the Gabardine DSS, a comprehensive GIS based decision support tool for MAR planning and management (Rusteberg et al., 2008).

\section{Acknowledgement}

The authors gratefully acknowledge the contribution of European Commission (EC) to fund the study under FP6 program, with the project entitled "Groundwater Artificial recharge Based on Alternative sources of wateR: aDvanced INtegrated technologies and management" (GABARDINE), contract no.518118. Sincere thanks to the National Laboratory of Civil Engineering (LNEC), Portugal for useful discussion and field data. We sincerely thank Nicolas Ryan (Göttingen) who, as a native speaker, made valuable suggestions that helped improve the English presentation of the manuscript with regard to both subject matter and style. The authors sincerely appreciate the helpful comments made by anonymous reviewers.

\section{References}

Almeida, C., Mendonça, J.L., Jesus, M.R., Gomes, A.J., 2000. Sistemas Aquíferos De Portugal Continental, Relatório. INAG, Instituto da Água, Lisboa. Electr. Doc. CD-ROM.

Anane, M., Kallali, H., Jellali, S., Ouessar, M., 2008. Ranking suitable sites for SAT in Jerba island (Tunisia) using GIS, Remote Sensing and AHP-multicriteria decision analysis. International Journal of Water $4(1 / 2), 121-135$.

Anbazhagan, S., Ramsamy, S.M., Gupta, S.D., 2005. Remote sensing and GIS for artificial recharge study, runoff estimation and planning in Ayyar Basin, Tamil Nadu, India. Environmental Geology 48, 158-170.

Anderson, M., Jones, M., Baxter, K., Gamble, D., 2005. Application of GIS to aquifer retention time, well recharge capacity and river depletion calculations to determine optimum locations for artificial recharge. In: 5th International Symposium, ISMAR 2005, pp. 777-782.
Bailey, D., Goonetilleke, A., Campbell, D., 2003. A new fuzzy multi-criteria evaluation method for group site selection in GIS. Journal of Multi-Criteria Decision Analysis 12 (6), 1-11.

Boroushaki, S., Malczewski, J., 2008. Implementing an extension of the analytica hierarchy process using ordered weighted averaging operators with fuzzy quantifiers in ArcGIS. Computers and Geosciences 34, 399-410.

Bouwer, H., 2002. Artificial recharge of groundwater: hydrogeology and engineering. Hydrogeology Journal 10, 121-142.

Brown, C.J., Weiss, R., Sutterfield, S., Verrastro, R., Kwiatkowski, P., Schubert, S., Alger Y., 2008. Development of an Aquifer, Storage and Recovery (ASR) site selection suitability index in support of the comprehensive everglades restoration project, Chapter 2, Aquifer Storage \& Recovery (ASR). Interim Report Supporting Documents. USA.

Calijuri, M.L., Marques, E.T., Lorentez, J.F., Azevedo, R.F., Carvalho, C.B., 2004. Multicriteria analysis for the identification of waste disposal areas. Geotechnical and Geological Engineering 22, 299-312.

CDPH (California Department of Public Health), 2008. Groundwater recharge reuse draft regulation. Website: http://www.cdph.ca.gov/certlic/drinkingwater/ Documents/Recharge/DraftRegulations.pdf (February 2010).

Chowdhury, A., Jha, M.K., Chowdhury, V.M., 2010. Delineation of groundwater recharge zones and identification of artificial recharge sites in West Medinipur District, West Bengal, using RS, GIS and MCDM techniques. Environmental Earth Science 59, 1209-1222.

Eastman, J.R., Kyem, P.A.K., Toledano, J., Jin, W., 1993. GIS and decision making United Nations Institute for Training and Research (UNITAR). Explorations in Geographic Information Systems Technology 4, 112.

Eastman, J.R., 1997. IDRISI for Windows, Version 2.0. Tutorial Exercises Graduate School of Geography, Clark University, Worcester, MA.

Eastman, J.R., 2000. Decision strategies in GIS. Column in directions magazine dated December 13, 2000. Available online at: http://www.directionsmag.com/ columns.php?column_id=38 (January 2010).

ESRI, 2004. ArcGIS Desktop Developer Guide: ArcGIS 9.1. ESRI, Redlands, CA.

Ghayoumian, J., Ghermezcheshme, B., Feizinia, S., Noroozi, A.A., 2005. Integrating GIS and DSS for identification of suitable for artificial recharge, case study Meimeh Basin; Isfahan, Iran. Environmental Geology 47, 493-500.

Ghayoumian, J., Saravi, M.M., Feizinia, S., Nouri, B., Malekian, A., 2007. Application of GIS techniques to determine areas most suitable for agricultural recharge in a Coastal Aquifer in Southern Iran. Journal of Asian Earth Sciences 30 364-374.

Gomes, E.G., Lins, M.P.E., 2002. Integrating geographical information systems and multi-criteria methods: a case study. Annals of Operations Research 116 243-269.

INAG, 2001. Plano Nacional Da Água. Lisboa, Instituto da Água - Direcção de Serviços de Recursos Hídricos, Ministério do Ambiente do Ordenamento do Território e do Desenvolvimento Regional. Webpage: http://www.inag.pt/ inag2004/port/a_intervencao/planeamento/pna/pna.html (June 2009).

Jankowski, P., Richard, L., 1994. Integration of GIS-based suitability analysis and multicriteria evaluation in a spatial decision support system for route selection. Environment and Planning B 21 (3), 326-339.

Jothiprakash, V., Marimuthu, G., Muralidharan, R., Senthil Kumar, N., 2003. Delineation of potential zones for artificial recharge using GIS. Journal of the Indian Society of Remote Sensing 31 (1), 37-47.

Jun, C., 2000. Design of an intelligent geographic information system for multicriteria site analysis. URISA Journal 12 (3), 5-17.

Kalantari, N., Rangzan, K., Thigale, S.S., Rahimi, M.H., 2010. Site selection and costbenefit analysis for artificial recharge in the Baghmalek Plain, Khuzestan Province, Southwest Iran. Hydrogeology Journal 18, 761-773.

Kallali, H., Anane, M., Jellali, S., Tarhouni, J., 2007. GIS-based multi-criteria analysis for potential wastewater aquifer recharge sites. Desalination 215, 111-119.

Krishnamurthy, J., Kumar, N.V., Jayaraman, V., Manive, M., 1996. An approach to demarcate ground water potential zones through remote sensing and a geographical information system. International Journal of Remote Sensing 17 (10), 1867-1884.

Lobo-Ferreira, J.P. Oliveira, L., 2007. Aquifer storage and recovery and applicability to Algarve (Portugal). In: Ribeiro, L., Chambel, A., Condesso de Melo, M.T. (Eds.), Proceedings XXXV IAH Congress. Groundwater and Ecosystems, Lisboa, p. 10 .

Malczewski, J., 1996. A GIS-based approach to multiple criteria group decision making International Journal of Geographical Information Systems 10, 955-971.

Malczewski, J., Chapman, T., Flegel, C., Walters, D., Shrubsole, D., Healy, M.A., 2003. GIS-multicriteria Evaluation with Ordered Weighted Averaging (OWA): case study of developing watershed management strategies. Environment and Planning A 35, 1769-1784.

Malczewski, J., 2004. GIS-based land-use suitability analysis: a critical overview. Progress in Planning 62, 3-65.

Malczewski, J., Rinner, C., 2005. Exploring multicriteria decision strategies in GIS with linguistic quantifiers: a case study of residential quality evaluation. Journal of Geographical System 7, 249-256.

Malczewski, J., 2006. Ordered weighted averaging with fuzzy quantifiers: GIS based multi-criteria evaluation for land use suitability analysis. International Journal of Applied Earth Observation 8, 270-277.

Monteiro, J.P., 2005. A Importacia Do Dimentionamento de Captacoes de Agus Subterraneas No Algarve - Passado, Presente e Futuro, Manual Técnico de Engenharia, Águas Subterrâneas e Efluentes Tratados da GRUNDFOS. Expresso Gráfico, Lisboa. 
Munda, G., 1995. Multicriteria Evaluation in a Fuzzy Environment. Physica-Verlag, Heidelberg. Contributions to Economics Series.

NRMMC, EPHC, NHMRC, 2009. Managed Aquifer Recharge Guidelines. Australian Guidelines for Water Recycling. Natural Resources Management Ministerial Council, Environment Protection and Heritage Council, and National Health and Medical Research Council. http://www.ephc.gov.au/taxonomy/term/39.

O'Hare, M.P., 1986. Site selection criteria for artificial recharge projects. In: Proceedings of the Association of Ground Water Scientists and Engineers, Southern Regional Groundwater Conference. National Water Well Association, Worthington OH, pp. 251-265.

Reddy, P.S., Pratap, D., 2006. Site suitability analysis for artificial recharge and water harvesting structures in hard rock terrain. Website: http://www. gisdevelopment.net/proceedings/mapindia/2006/student\%20oral/mi06stu_132. htm (October 2009).

Rinner, C., Malczewski, J., 2002. Web-enabled spatial decision analysis using ordered weighted averaging. Journal of Geographical Systems 4, 385-403.

Rusteberg, B., Rahman, M.A., Bear, J., Bensabat, J., Brouyère, S., Wojda, P., Gogu, R.C., Power, H., 2008. The gabardine decision support system for artificial recharge planning and management. In: Conference on Water Reclamation and Aquifer Recharge, Maribor, Slovenia.

Saaty, T.L., 1980. The Analytical Hierarchy Process. Mcgraw-Hill, New-York.

Saraf, A.K., Choudhury, P.R., 1998. Integrated remote sensing and GIS for the groundwater exploration and identification of artificial recharge sites. International Journal of Remote Sensing 19 (10), 1825-1841.

Shankar, M.N.R., Mohan, G., 2005. A GIS based hydrogeomorphic approach for identification of site-specific artificial-recharge techniques in the Deccan Volcanic Province. Journal of Earth System Science 114 (5), 505-514.

Sharifi, M.A., Retsios, V., 2004. Site selection for waste disposal through spatial multiple criteria decision analysis. Journal of Telecommunications and Information Technology 3, 1-11.
Sharifi, M.A., Boerboom, L., Shamsudin, K.B., Veeramuthu, L., 2006. Spatial multiple criteria decision analysis in integrated planning for public transport and land use development study in Klang Valley, Malaysia. In: ISPRS Technical Commission II Symposium, Vienna, pp. 85-91.

Shrier, C., Fontane, D., Garcia, L., 2008. Spatial knowledge-based decision analysis system for pond site assessments. Journal of Water Resources Planning \& Management 134 (1), 14-213.

Store, R., Kangas, J., 2001. Integrating spatial multi-criteria evaluation and expert knowledge for GIS-based habitat suitability modeling. Landscape and Urban Planning 55, 79-93.

Water Framework Directive (WFD), 2003. Overall Approach to the Classification of Ecological Status and Ecological Potential, WFD Common Implementation Strategy, Working Group 2A. Ecological Status (ECOSTAT), pp. 52.

Werz, H., Rapp, M., Wolf, L., Ali, W., Hötzl, H., 2009. Evaluation of potential sites for managed aquifer recharge (MAR) using surface infiltration in NW-Jordan. In: Proceeding of EWRA Seventh Conference on "Water Resources Conservancy and Reduction Under Climatic Uncertainty”, Limassol, Cyprus, June, 25-27, pp. 55-62.

Wood, W.W., 1980. Development of technical site selection criteria for artificial recharge: wastewater reuse for groundwater recharge. In: Proceedings of the Symposium held on September 6-7, 1979 at California State Polytechnic University at Pomona. California State Water Resources Control Board, Office of Water Recycling, Sacramento, pp. 73-79.

Yager, R.R., 1988. On ordered weighting averaging aggregation operators in the multicriteria decision making. IEEE Transactions on Systems, Man and Cybernetics $18,183-190$

Zadeh, L.A., 1983. A computational approach to fuzzy quantifiers in natural languages. Computers \& Mathematics with Applications 9, 149-184.

Zucca, A., Sharifi, M.A., Fabbri, A.G., 2007. Application of spatial multi criteria analysis to site selection for a local park: a case study in the Bergamo Province, Italy. Journal of Environmental Management 88 (4), 752-769. 